\title{
RECONSTRUCCIÓN FONOLÓGICA DEL PIDGIN AFROPORTUGUÉS AMERICANO: LAS CONSONANTES
}

\author{
Mario Portilla
}

\begin{abstract}
RESUMEN
En el presente artículo presenta la reconstrucción de las protoconsonantes de un pidgin afroportugués utilizado en América durante el siglo XVII mediante la aplicación del Método Comparativo.

Palabras clave: Lenguas criollas, pidgin portugués, reconstrucción fonológica, saramaca, papiamento, palenquero.
\end{abstract}

\begin{abstract}
This article provides the proto-conosonant reconstruction of an Afro-Portuguese pidgin spoken in the Americas in the XVII Century according to the principles of the Historical Comparative Method.

Key words: Creole languages, Portuguese pidgin, phonological reconstruction, saramaccan, papiamentu, palenquero.
\end{abstract}

\section{Introducción}

La exploración y colonización portuguesas de ultramar desde principios del siglo XV dio como resultado la utilización de variedades pidgnizadas de la lengua portuguesa tanto en África, y eventualmente también en América (Perl 1989b), como en Asia y en varios territorios en el Pacífico ${ }^{1}$. La mayor parte de las evidencias tanto históricas como lingüísticas apuntan al hecho de que las variedades utilizadas en el Atlántico provienen de un pidgin distinto de aquel usado en Asia y el Pacífico (cf. Stolz 1987, Bartens 1995, Lipski 2002, Clements 1999 y 2000).

Dr. Mario Portilla. Profesor Catedrático de la Escuela de Filología, Lingüística y Literatura, Universidad de Costa Rica. San Pedro, San José, Costa Rica.

Correo electrónico: marioportilla2000@yahoo.com

Recepción: 26- 2- 2009

Aceptación: 14- 4- 2009 
Portilla 2008 ha mostrado evidencia lingüística que prueba un ineludible parentesco entre el saramaca (Surinam), el papiamento (Antillas Holandesas) y el palenquero (Colombia) ${ }^{2}$. Estas tres las lenguas criollas americanas provienen de un mismo protopidgin afroportugués. Portilla 2008 ha logrado determinar un vocabulario común para estas tres variedades (unos 27 rubros), el cual presenta particularidades que solo comparten estas lenguas y que son ajenas al portugués estándar y al español.

La información histórica y demográfica ${ }^{3}$ indica que estos tres criollos pueden perfectamente provenir de una misma variedad de pidgin portugués utilizada en América entre mediados del siglo XVII y principios del siglo XVIII.

\section{Propósito de la investigación}

Portilla 2007 presenta la reconstrucción del sistema vocálico del protopidgin afroportugués americano que dio origen al saramaca, el papiamento y el palenquero. El objetivo de estetrabajo es establecer, entonces, la reconstrucción del sistema consonántico de esta misma protolengua. Con ello, se completa la reconstrucción de todo el sistema segmental del protopidgin afroportugués americano, mediante la aplicación del Método Comparativo.

Los materiales para la comparación son la lista de cognados que aparece en Portilla 2007, 2008 y otros que han podido ser establecidos para este trabajo. Todos los rubros comparados han sido tomados de las siguientes fuentes: Para el saramaca, los datos son de Huttar (1972), el Saramaccan - English Dictionary del SIL (Summer Institute of Linguistics) y Taylor (1977); para el papiamento son de Maurer (1998b), Maduro (1987), el PapiamentoEnglish/ English-Papiamento lexicon y el Amaro's papiamentu project; y para el palenquero son de Maduro (1987), Cásseres (2005), Megenny (1986) y Friedemann \& Patiño (1983).

\section{Los sistemas fonológicos de las variedades comparadas ${ }^{4}$}

\subsection{El saramaca}

El sistema vocálico de este criollo ${ }^{5}$ consta de siete vocales orales, que se caracterizan con los rasgos distintivos [+/-anterior], [+/-posterior], [+/-alto], [+/-bajo] y [+/-tenso] (cuadro 1.1). También, en esta lengua, existe el contraste entre vocales cortas y largas [+/-largo]. Sin embargo, dado que cada mora de las vocales largas puede presentar un tonema distinto, se han preferido aquí interpretar las vocales largas como una secuencia de dos vocales iguales.

\section{Cuadro 1.1.}

Vocales del saramaca

[+alto]
[-alto [+tenso]
[-bajo] [-tenso]
[+bajo]

$\begin{array}{cc}\text { [+anterior] } & \\ \mathrm{i} & \\ \mathrm{e} & \\ \varepsilon & \mathrm{a}\end{array}$

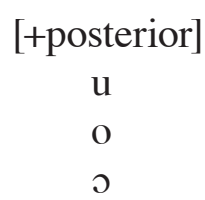

El sistema consonántico consta de 27 segmentos: seis oclusivas simples, dos africadas, dos labiovelares, cuatro fricativas, cuatro oclusivas prenasalizadas, tres nasales, una lateral y tres aproximantes (cuadro 1.2). 


\section{Cuadro 1.2}

Consonantes del saramaca

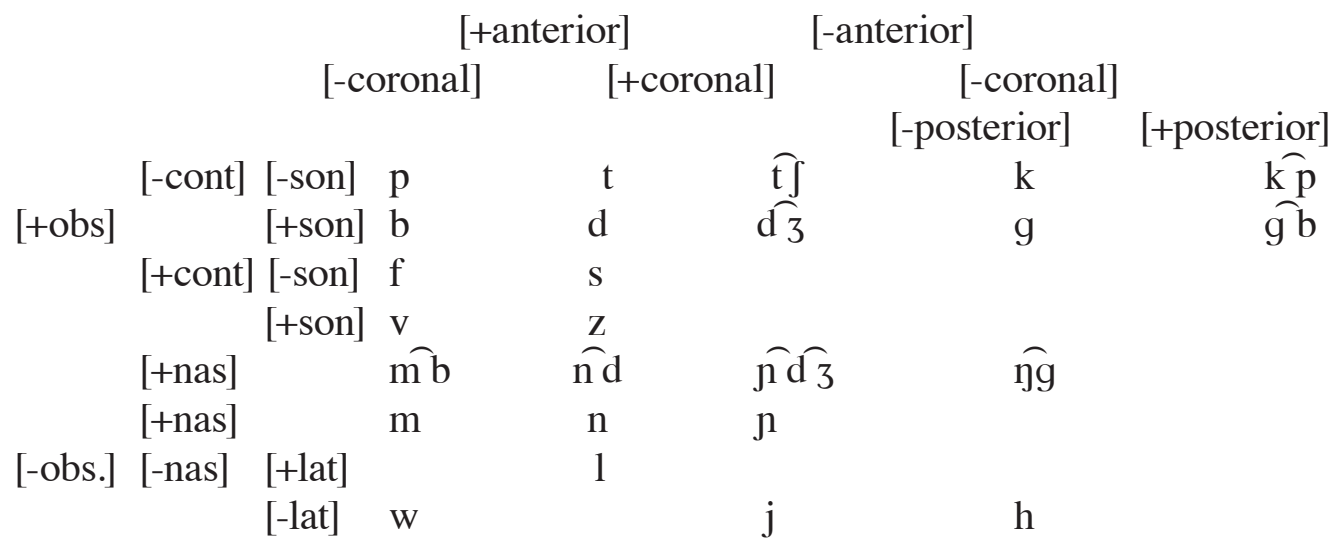

El saramaca presenta además dos tonos de nivel con carácter fonémico: uno alto (marcado aquí con una tilde) y uno bajo (no marcado gráficamente), los cuales ocurren sin restricción de aparición en cualquier sílaba de la palabra.

$\begin{array}{ll}\text { tú } & \text { dos } \\ \text { tu } & \text { también } \\ \text { maaká } & \text { notar } \\ \text { maá ka } & \text { presagio } \\ \text { maká } & \text { espina }\end{array}$

\subsection{El papiamento}

El papiamento ${ }^{6}$ presenta un sistema de nueve fonemas vocálicos, los cuales se distinguen por los siguientes rasgos distintivos: [+/-anterior], [+/-posterior], [+/-alto], [+/-bajo], [+/-tenso] y [+/-redondeado] (cuadro 1.3). Maurer 1998b menciona que los fonemas vocálicos / $\mathrm{y}, \phi /$ se utilizan solamente en préstamos holandeses y en un registro de habla culta.

\section{Cuadro 1.3.}

Vocales del papiamento

$\begin{array}{lcccc} & \text { [+anterior] } & & \text { [+posterior] } \\ & \text { [-red] } & \text { [+red] } & \\ \text { [+alto] } & \mathrm{i} & \mathrm{y} & \mathrm{u} \\ \text { [-alto [+tenso] } & \mathrm{e} & \varnothing & & \mathrm{o} \\ \text { [-bajo] [-tenso] } & \varepsilon & & & 0 \\ \text { [+bajo] } & & & \mathrm{a} & \end{array}$

Esta lengua presenta 23 consonantes: seis oclusivas simples, dos africadas, siete fricativas, tres nasales, una lateral, una vibrante múltiple y tres aproximantes (cuadro 1.4). 


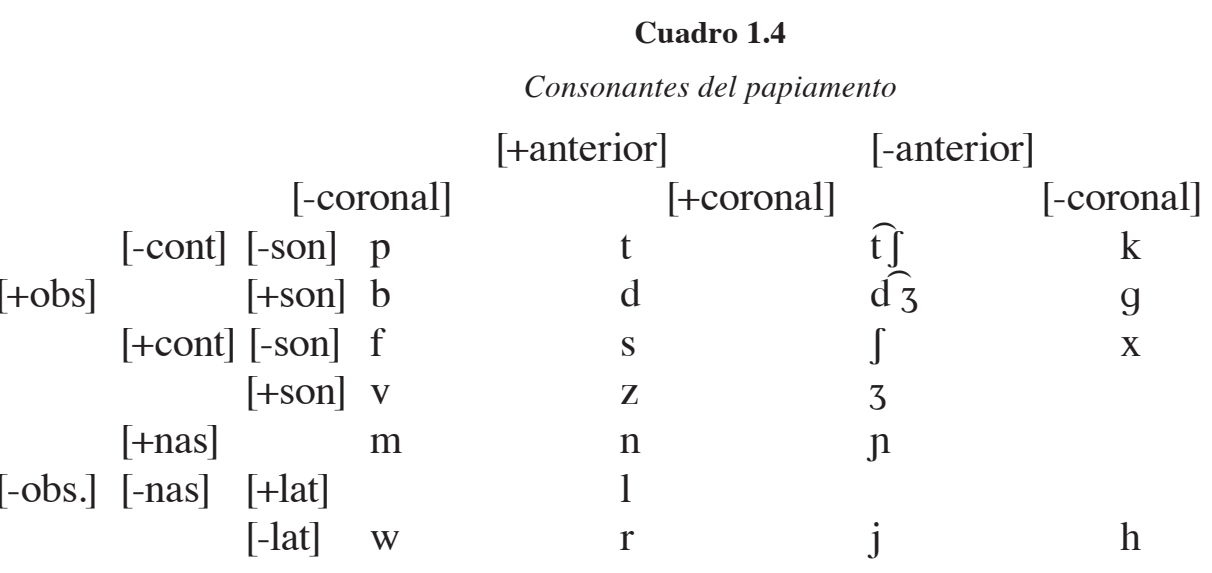

Para establecer una comparación más homogénea entre las variedades, en este trabajo, las paravocales [ $\mathrm{w}, \mathrm{j}$ ] son consideradas manifestaciones fonéticas de las vocales / u, i / respectivamente, cuando aparecen formando diptongo con otras vocales y en posición no inicial de sílaba (cf. Maurer 1998: 148). Pero, en posición inicial de sílaba. se representan como fonemas autónomos / w, j/.

En cuanto a los suprasegmentales, esta lengua presenta, por un lado, un acento de intensidad de carácter contrastivo por palabra (representado aquí por una comilla antes de la sílaba acentuada, tal como se recomienda en el Alfabeto Fonético Internacional). En la mayor parte de los casos, la colocación del acento ocurre en la penúltima sílaba cuando la palabra termina en vocal o en -er, -el y -en (en cuyo caso o bien la vocal tiende a debilitarse o bien estos sonidos son sustituidos por la vocal -u) y en la última sílaba cuando la palabra termina en consonante. La mayor parte de las excepciones a estas reglas la constituyen verbos de tres o cuatro sílabas terminados en vocal, los cuales llevan el acento en la última sílaba. También, hay un número considerable de sustantivos (y participios) de dos sílabas terminados en vocal que llevan el acento en la última sílaba.

$\begin{array}{ll}\text { ku'minda } & \text { comida } \\ \text { kumin'da } & \text { saludar } \\ \text { 'mata } & \text { matar } \\ \text { ma'ta } & \text { matado } \\ \text { 'həmber } & \text { hombre } \\ \text { mu'he } & \text { mujer }\end{array}$

Además, esta lengua presenta dos tonemas: un tono alto (representado aquí con una tilde) y un tono bajo (sin representación gráfica). En muchas ocasiones el tono alto aparece en la vocal de la sílaba acentuada, pero en el caso de los verbos, y de algunos pocos sustantivos, pronombres y adverbios, el tono alto recae sobre la última vocal inacentuada.

$\begin{array}{ll}\text { 'máta } & \text { mata, planta } \\ \text { 'matá } & \text { matar } \\ \text { ma'tá } & \text { matado } \\ \text { 'pára } & \text { pájaro } \\ \text { 'pará } & \text { parar }\end{array}$




$\begin{array}{ll}\text { pa'rá } & \text { parado } \\ \text { 'muțá } & \text { muchacho } \\ \text { 'bosó } & \text { ustedes } \\ \text { 'akí } & \text { aquí }\end{array}$

A diferencia del saramaca, el papiamento presenta la restricción de la aparición de un solo tono alto por palabra polisílaba, lo cual indica que esta lengua es del tipo llamado de acento tonal.

\subsection{El palenquero}

Los diversos autores ${ }^{7}$ coinciden en que el palenquero presenta un sistema fonológico muy cercano al descrito para el llamado español del Caribe. El sistema vocálico está compuesto por cinco segmentos, los cuales se diferencian por los rasgos distitivos: [+/-anterior], [+/-posterior], [+/-alto] y [+/-bajo] (cuadro 1.5).

\section{Cuadro 1.5.}

\section{[+alto] \\ [-alto, -bajo]}

[+bajo]
Vocales del palenquero

$\begin{array}{cc}\text { Vocales del palenquero } \\ \text { [+anterior] } \\ \mathrm{i} & \\ \mathrm{e} & \mathrm{a}\end{array}$

\section{[+posterior]}

$\mathrm{u}$

o

El sistema consonántico está compuesto por 17 segmentos: seis oclusivas simples, dos africadas, dos fricativas, tres nasales, una lateral, una vibrante múltiple, una vibrante simple y una aproximante (cuadro 1.6).

\section{Cuadro 1.6}

Consonantes del palenquero

\begin{tabular}{|c|c|c|c|c|c|c|}
\hline & & & & ior] & & \\
\hline & & [-coron & & [+coronal] & & [-coronal] \\
\hline & [-cont $]$ & [-son] & $\mathrm{p}$ & $\mathrm{t}$ & $\widehat{\mathrm{t} J}$ & $\mathrm{k}$ \\
\hline [+obs] & & [+son] & $\mathrm{b}$ & $\mathrm{d}$ & $\mathrm{d} 3$ & g \\
\hline & [+cont $]$ & [-son] & $f$ & $\mathrm{~S}$ & & \\
\hline & [+nas] & & $\mathrm{m}$ & $\mathrm{n}$ & $\mathrm{n}$ & \\
\hline [-obs.] & [-nas] & [+lat] & & 1 & & \\
\hline & & [-lat] & [+tenso] & $r$ & & \\
\hline & & & [-tenso] & r & & $\mathrm{h}$ \\
\hline
\end{tabular}

Es importante señalar dos aspectos en relación con las consonantes del palenquero ${ }^{8}$. En primer lugar, todos los autores mencionan la existencia de consonantes prenasalizadas, especialmente de una serie de oclusivas sonoras prenasalizadas [ $\widehat{\mathrm{mb}}, \widehat{\mathrm{nd}}, \widehat{\mathrm{yg}}]^{9}$. Estas aparecen en posición inicial de palabra (inicial absoluta y después de vocal), pero alternando más o menos libremente con las oclusivas sonoras correspondientes. Para fines comparativos, se ha optado en este trabajo por representar fonológicamente estas oclusivas prenasalizadas como la secuencia de una nasal y una oclusiva sonora /mb, nd, ng/: 


$\begin{array}{ll}\text { mbósa } & \text { bolsa } \\ \text { mbosá } & \text { bozal } \\ \text { ndoló } & \text { dolor } \\ \text { ndá } & \text { dar } \\ \text { ngánde } & \text { grande } \\ \text { ngúba } & \text { maní }\end{array}$

Por otro lado, es muy probable que la consonante vibrante múltiple / r / haya sido introducida en palenquero recientemente por influencia del superestrato español, ya que este segmento suele ser reemplazado por el fonema lateral / 1 / en gran parte de los étimos de vocabulario más básico.

$\begin{array}{ll}\text { pélo } & \text { perro } \\ \text { balé } & \text { barrer } \\ \text { kulé } & \text { correr } \\ \text { ngalá } & \text { agarrar }\end{array}$

En cuanto a los suprasegmentales, Bickerton y Escalante 1968 sostienen que esta lengua presenta un acento melódico más que de intensidad. Aunque Friedemann y Patiño 1983 señalan que el palenquero tiene un acento espiratorio que no difiere notablemente del español, la misma breve caracterización que estos autores ofrecen de la entonación de esta lengua, permite suponer que el palenquero sea una lengua de acento tonal. Esto significa que, como en el caso del papiamento, un tono alto (o un acento de altura) tiene una aparición restringida a una sílaba por palabra polisílaba. Por ello, y para facilitar la comparación de los cognados, se ha decidido representar aquí el acento por medio de una tilde (que es el símbolo que corresponde a un tono alto, según lo recomendado en el Alfabeto Fonético Internacional).

\section{Las protoconsonantes}

Para el pidgin afroportugués americano, es posible reconstruir un sistema 19 consonantes: seis oclusivas simples, una africada, seis fricativas, tres nasales, una lateral, una vibrante múltiple y una aproximante (cuadro 2.1).

\section{Cuadro 2.1}

Protovocales del pidgin afroportugués americano

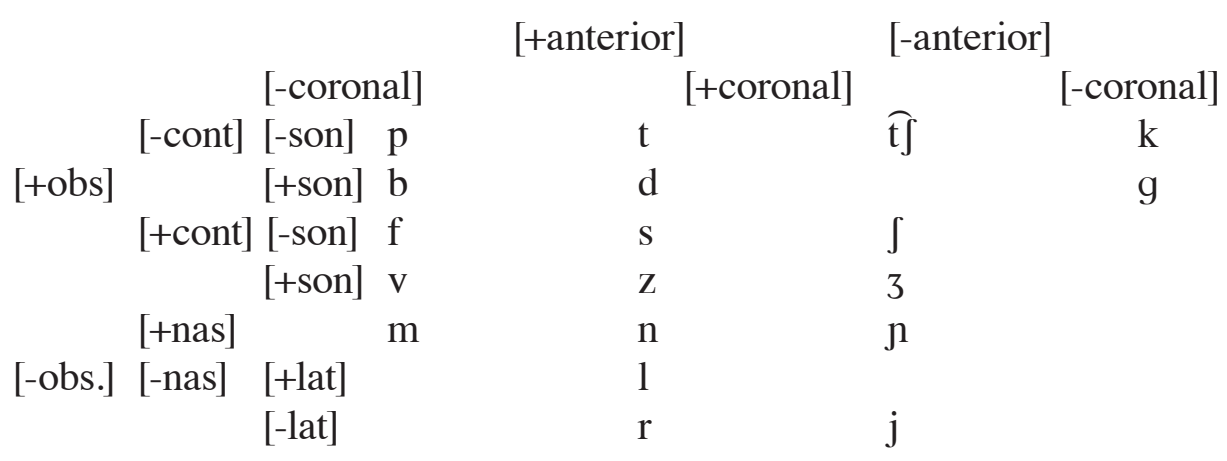

Las protoconsonantes presentan las siguientes correspondencias en las variedades comparadas: 
3.1. * p $^{2}$

$\begin{array}{lllll}\text { saramaca } & \text { papiamento } & \text { palenquero } & & \\ \text { a. } & \text { / p / } & \text { / p / } & & \\ \text { papiá } & \text { 'papiá } & \text { papiá10 } & \text { *papiá } & \text { hablar, charlar } \\ \text { pasá } & \text { 'pasá } & \text { pasá } & \text { *pasá } & \text { pasar } \\ \text { paká } & \text { 'pagá } & \text { pagá } & \text { *pagá } & \text { pagar } \\ \text { patupátu } & \text { 'pátu, } & (-)^{12} & \text { *pátu } & \text { pato } \\ \text { pái } & \text { 'páto } & & & \\ \text { papakái } & \text { 'pay'13 } & \text { páe } & \text { *pái } & \text { padre } \\ \text { pidí } & \text { 'papagái } & \text { (papagád3o) } & \text { *papagái } & \text { papagayo } \\ \text { (písi) } & \text { 'pidídá } & \text { pirí } & \text { *pidí } & \text { pedir } \\ \text { pusá } & \text { 'pufá } & \text { piá } & \text { *pidá } & \text { pedazo } \\ \text { (ákisi, } & \text { 'puntrá } & \text { (puhá) } & \text { *pufá } & \text { empujar } \\ \text { hákisi) } & & \text { plundá, } & \text { *pruntá16 } & \text { preguntar } \\ \text { puúma } & \text { 'plúma } & \text { plúma } & \text { *plúma } & \text { pluma }\end{array}$

La protoconsonante *p se conserva idéntica en las tres lenguas en posición inicial de palabra, seguida de vocales (*pasá); en posición intermedia en medio de vocales (*papiá); y en posición tautosilábica con una líquida (*plúma).

$\begin{array}{lllll}\text { b. } / \mathrm{p} \sim \mathrm{b} / & / \mathrm{p} / & (-) & & \\ \text { límbo, } & \text { límpi } & \text { (límpio, } & \text { *límpu } & \text { limpio } \\ \text { límpo } & & \text { límpiu) } & & \\ \text { kómpe } & \text { 'kómpai } & \text { (amígo) } & \text { *kómpai } & \text { amigo }\end{array}$

En saramaca, la protoconsonante *p se sonoriza facultativamente cuando está precedida por una consonante nasal (*límbo, *kómpe). Hay que recordar que en esta lengua existe toda una serie de consonantes oclusivas prenasalizadas sonoras, las cuales aparecen en rubros que provienen de lenguas africanas, especialmente de lenguas de la familia nigercongo (cf. supra).

Otros ejemplos de este cambio en saramaca son los siguientes:

$\begin{array}{ll}\text { limbá } & <\text { port. limpar 'limpiar'17 } \\ \text { dzómbo } & <\text { ing. jump 'saltar' }\end{array}$

Sin embargo, en la mayor parte de los rubros, provenientes del portugués y del inglés, la sonorización de *p no ocurre.

$\begin{array}{ll}\text { kámpu } & \text { < port. campo 'campo'18 } \\ \text { kompási } & \text { < port. compas 'compás'19 } \\ \text { lámpu } & \text { < ing. lamp 'lámpara de kerosén' } \\ \text { tómpi } & \text { < ing. stump 'cojo, cojear' } \\ \text { kaámpi } & \text { < ing. clamp 'grapa, engrapar' } \\ \text { sitámpu } & \text { < ing. stamp 'patear, pisotear' } \\ \text { suwámpu } & \text { < ing. swamp 'pantano' }\end{array}$




\section{2. $* \mathbf{b}$}

\begin{tabular}{|c|c|c|c|c|}
\hline saramaca & papiamer & \multicolumn{3}{|l|}{ palenquero } \\
\hline / b / & / b / & \multicolumn{3}{|l|}{$/ \mathrm{b} /$} \\
\hline baíka $\mathrm{ka}^{20}$ & ba'rỉka & \multirow{2}{*}{$\begin{array}{l}\text { baríka } \\
\text { (búlo) }\end{array}$} & *barỉka & estómago, barriga \\
\hline bulíki & $\begin{array}{l}\text { bu'ríku, } \\
\text { bu'rík ko }\end{array}$ & & *burỉku & burro, borrico \\
\hline búnu & 'bón & \multirow{2}{*}{$\begin{array}{l}\text { (búeno) } \\
\text { (ngopiá) }\end{array}$} & *bón & \multirow{2}{*}{$\begin{array}{l}\text { bueno } \\
\text { golpear }\end{array}$} \\
\hline batí & 'batí & & *batí & \\
\hline bakajáu & \multicolumn{2}{|c|}{ 'bakijou ${ }^{22}$} & \multicolumn{2}{|c|}{ *bakajáu } \\
\hline baáku & 'buráku & $(-)$ & *buráku & hиeco \\
\hline bebé & 'bebé & bebé & *bebé & beber \\
\hline kabá & 'kabá & kabá & *kabá & acabar \\
\hline líba & 'rỉba & ríba & *ríba & sobre, encima de \\
\hline sábi & $\begin{array}{l}\text { 'sábi, } \\
\text { 'sá }\end{array}$ & sábe & *sábi & saber \\
\hline subí & 'subí & $(-)$ & *subí & subir \\
\hline lábu & $\begin{array}{l}\text { 'rábu, } \\
\text { 'rábo }\end{array}$ & lábo & *rábu & rabo \\
\hline tabáku & $\begin{array}{l}\text { ta'báku, } \\
\text { ta'báko }\end{array}$ & $(-)$ & *tabáku & tabaco \\
\hline $\mathrm{t} \int \mathrm{úmbu}^{23}$ & $\begin{array}{l}\text { 'tfúmbu, } \\
\text { 'tfúmbo }\end{array}$ & $(-)$ & *t $\int u ́ m b u$ & plomo \\
\hline lembé & 'lembé & $(-)$ & *lembé & lamer $^{24}$ \\
\hline jabí $i^{25}$ & 'habrí & abrí & *abrí & abrir \\
\hline "sómbra'26 & 'sómbra & $(-)$ & *sómbra & sombra \\
\hline 'kubri'27 & 'kubrí & $(-)$ & *kubrí & cubrir \\
\hline
\end{tabular}

La protoconsonante *b se conserva de manera idéntica en saramaca, papiamento y palenquero en todas las posiciones posibles de la palabra: en posición inicial, seguida de vocal (*baríka); en posición media, precedida de vocal (*rábu) o de consonante (*t túmbo); y en posición tautosilábica con una líquida (*kubrí) ${ }^{28}$.

\section{3. $* \mathrm{t}$}

saramaca papiamento palenquero

a. $/ \mathrm{t} / \mathrm{t} / \mathrm{t} / \mathrm{t} /$

$\begin{array}{lllll}\text { ta } & \text { 'ta } & \text { ta } & \text { *ta } & \text { aspecto progresivo }{ }^{29} \\ \text { téla } & \text { 'téra } & \text { (tiéla) } & \text { *téra } & \text { tierra } \\ \text { té } & \text { 'té } & \text { (áta, áhta) } & \text { *té } & \text { hasta } \\ (\text { dé }) & \text { 'tín } & \text { tén } & \text { *tén } & \text { tener } \\ \text { butá } & \text { 'butá30 } & \text { (poné) } & \text { *butá } & \text { poner } \\ \text { patupátu } & \text { 'pátu, } & (-) & \text { *pátu } & \text { pato } \\ & \text { 'páto } & & & \\ \text { gumbitá } & \text { 'gumbitá } & (-) & \text { *gumbitá } & \text { vomitar } \\ \text { fuúta } & \text { 'frúta } & \text { frúta } & \text { *frúta } & \text { fruta } \\ \text { tiîpa } & \text { 'trípa } & (-) & \text { *túta } & \text { intestinos }\end{array}$


La protoconsonante $* t$ se conserva idéntica en las tres lenguas en posición inicial absoluta ante vocal $(*$ ta), en posición intervocálica (*butá) y en posición tautosilábica con una consonante líquida (*frúta).

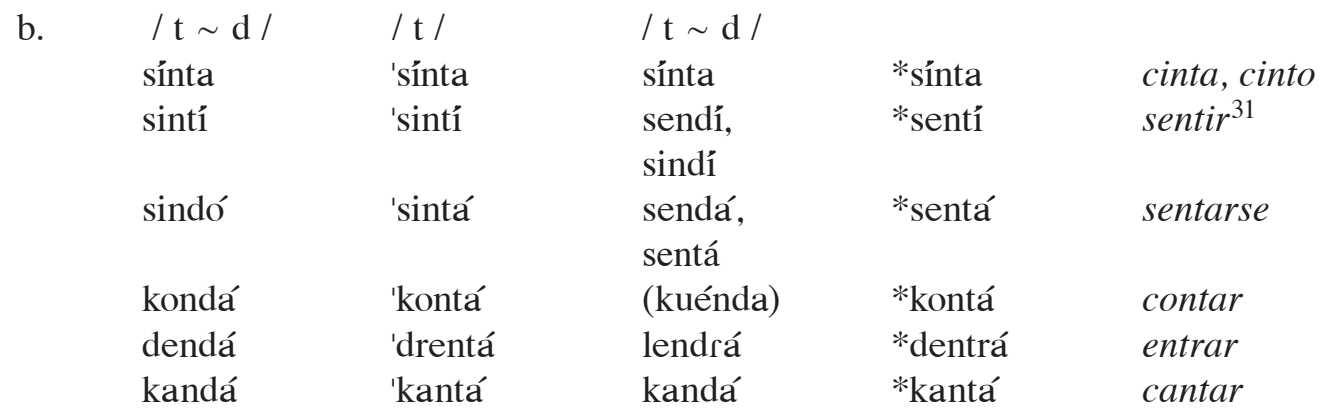

Al igual que ocurre con lo descrito para la *p en 3.1., la sonorización de la protoconsonante *t está condicionada por la consonante nasal precedente. Aunque tanto en saramaca como en palenquero la protoconsonante *t se realiza tanto con las formas / t / y / d /, en ambas lenguas predominan las realizaciones con el segmento sonoro. Por otro lado, en papiamento, la sonorización de *t es más bien esporádica, y ocurre más bien en rubros de origen hispánico.

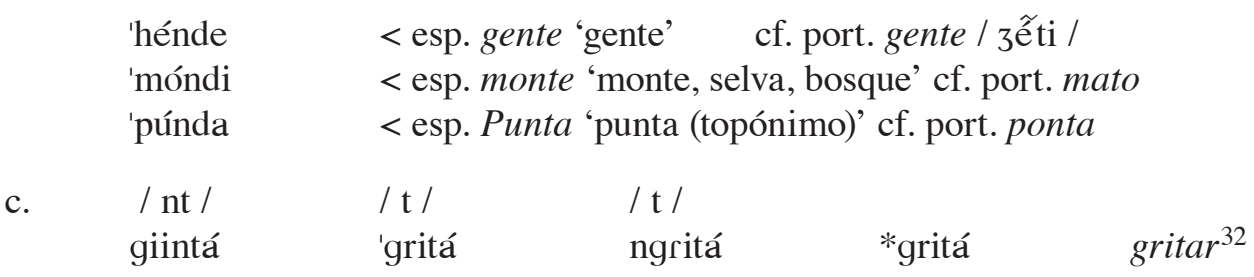

En las fuentes consultadas, solamente en esta ocasión, el protosegmento *t se realiza como una consonante prenasalizada en saramaca.

\section{4. $\quad * d$}

saramaca papiamento palenquero

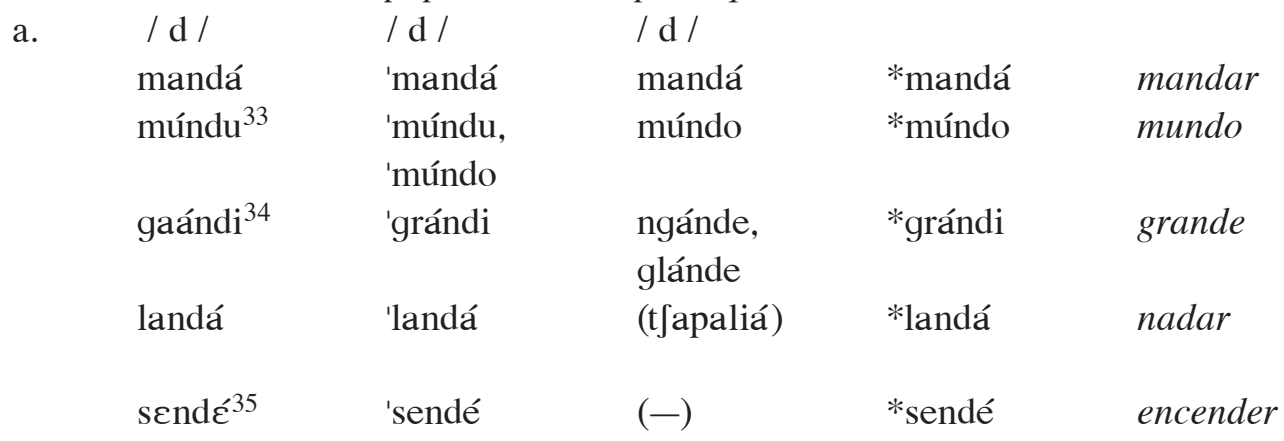

La protoconsonante *d se conserva de manera idéntica en las tres lenguas cuando está precedida por una consonante nasal. 


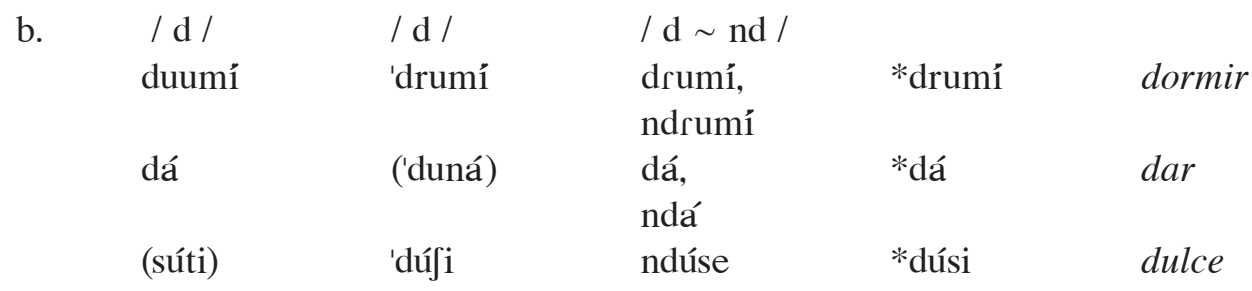

En posición inicial de palabra, la protoconsonante *d se conserva idéntica en saramaca y papiamento, mientras que en palenquero hay una alternancia entre una consonante oclusiva sonora y una oclusiva prenasalizada sonora, cuando esta va seguida de una vocal no anterior.

$\begin{array}{lllll}\text { c. / d / } & \text { / d / } & / 1 \sim \text { / } & & \\ \text { dendá } & \text { 'drentá } & \text { lendrá } & \text { *dentrá } & \text { entrar } \\ \text { déndu }^{36} & \text { (a'dén) } & \text { léndro } & \text { *déntru } & \text { dentro } \\ \text { didía }^{37} & \text { di'día } & (-) & \text { *didía } & \text { día } \\ \text { (dáka) } & \text { 'día } & \text { ría, (dí) } & * \text { día } & \text { día } \\ \text { (fu) } & \text { di } & \text { ri, (di, } & * \text { di } & \text { de }\end{array}$

En palenquero, en posición inicial de palabra, pero seguida de una vocal anterior, la protoconsonante $* d$ se realiza como una lateral o una vibrante simple. Como se ha dicho, en saramaca y en papiamento, esta protoconsonante se conserva de manera idéntica en esta posición.

$\begin{array}{lllll}\text { d. } \quad \text { / d } \sim \varnothing / & / \mathrm{d} / & \text { / } \sim \varnothing / & & \\ \text { pidí } & \text { 'pidí } & \text { pirí } & \text { *pidí } & \text { pedir } \\ \text { sakwí } & \text { 'sakudí } & (-) & \text { *sakudí } & \text { sacudir } \\ \text { (písi) } & \text { pi'dá } & \text { piá } & \text { *pidá } & \text { pedazo }\end{array}$

En posición intervocálica, la protoconsonante *d se mantiene idéntica en papiamento. En saramaca, en algunos casos se mantiene idéntica y en otros desaparece, después de haber pasado a ser una consonante líquida $(\mathrm{r} \sim \mathrm{l})$. En palenquero, esta se convierte en una vibrante cuando va seguida de la vocal / i / y desaparece cuando sigue una vocal no anterior.

En saramaca, el cambio $* \mathrm{~d}>\mathrm{r} \sim 1>\varnothing$ puede ser notado al confrontar algunas formas actuales con las recogidos por Riemer 1779 y con el portugués, tal como se observa a continuación:

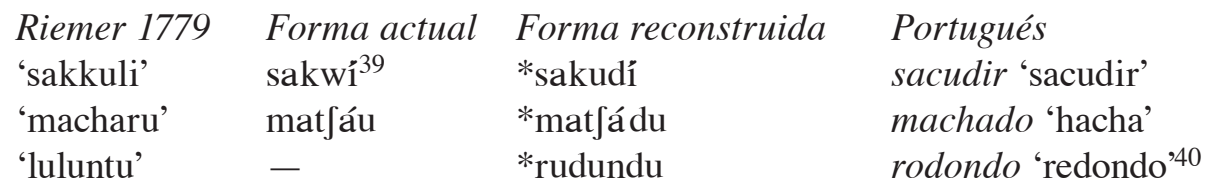

Ocasionalmente, el cambio ocurre también en rubros de origen inglés:

$\begin{array}{llll}\text { Riemer } 1779 & \text { Forma actual } & \text { Forma reconstruida } & \text { Inglés } \\ \text { 'brara' } & \text { baáa } & \text { *broída d1 } & \text { brother 'hermano' } \\ \text { 'bredi' } & \text { bé́c } & \text { *bréd } & \text { bread 'pan' } \\ \text { 'brâli, brâri, } & \text { baái } & \text { *bró:d } & \text { broad 'ancho, amplio' } \\ \text { brâdi, bladi' } & & & \end{array}$


Sin embargo, como se ha dicho, en otras ocasiones la protoconsonante *d se mantiene idéntica en saramaca en posición intervocálica al igual que en otras posiciones. Esto es evidente en rubros que provienen indudablemente del portugués.

\begin{tabular}{|c|c|}
\hline pikádu & $<$ port. pecado 'clase de maldición familiar \\
\hline papáda & < port. papada 'paperas' \\
\hline sikáda & < port. escada 'escalera' \\
\hline amánda & < port. amênda 'almendra' \\
\hline disá & < port. deixar 'dejar' \\
\hline doba $a^{43}$ & $<$ port. dobrar 'doblar' \\
\hline póndi ${ }^{44}$ & < port. podre 'podrido' \\
\hline nandú & < port. maduro 'maduro' \\
\hline
\end{tabular}

Las dos últimas formas citadas muestran un posible fenómeno de prenasalización de una protoconsonante $* \mathrm{~d}$ cuando este segmento se halla en posición intermedia de palabra y seguido de una consonante vibrante, según la siguiente derivación:

port. podre $>\quad *$ pódri $>$ póndri (1779) $>$ póndi

port. maduro $>$ *madúru $>$ *madúrú $>$ *madrú $>$ mandrú (1779) > mandú

Este fenómeno de prenasalización descrito aquí es semejante al que ocurre en el caso de la protoconsonte *g (cf. $3.6 \mathrm{~d}$ ).

Para el caso del papiamento y del palenquero, el problema consiste en que no hay seguridad de que los rubros que contienen los posibles reflejos de una $*$ d provengan del portugués o del español, pues son idénticos en ambas lenguas. De hecho, tampoco hay total certeza de que los términos correspondientes al rubro pedazo provengan del protopidgin afroportugués original, dado que no se encuentra una forma equivalente en saramaca ${ }^{45}$.

\section{5. $* \mathbf{k}$}

saramaca papiamento palenquero

a. $/ \mathrm{k} / \mathrm{k} / \mathrm{k} / \mathrm{k} /$

kaí 'kaí kaí

kulá 'kurá

kulé

$\mathrm{ku}$

'kurí ${ }^{46}$

ké

$\mathrm{ku}$

'ké

kabá

kákísa ${ }^{47}$

kəm $\varepsilon^{48}$

'kabá

'káska

'komé

kómpe 'kómpai

kondá

akí

baíka

makáku

'kontá

'akí

ba'ríka

kaí

kulá

kulé

$\mathrm{ku}$

(kelé)

kabá

$(-)$

kumé,

*kaí

caer

*kurá

curar

*kuré

correr

$* \mathrm{ku}$

con

*ké

*kabá

querer

*káska

acabar

komé

*komé

corteza

(amígo)

(kuénda)

akí

ma'káku,

baríka

(móno)

*kómpai

comer

ma'káko

tabáku

ta'báku,

(-)

*kontá

amigo

*akí

contar

*baríka

*makáku

aqui

barriga

mono

ta'báko

*tabáku

tabaco 


\begin{tabular}{|c|c|c|c|c|}
\hline bulíki & $\begin{array}{l}\text { bu'rỉku, } \\
\text { bu'rỉ ko }\end{array}$ & (búlo) & *buríku & burro, borrico \\
\hline (díki) & 'kobá & kobá & *kobá & cavar \\
\hline bakajáu & \multicolumn{2}{|c|}{ 'bakijou } & \multicolumn{2}{|c|}{ kajáu } \\
\hline baáku & 'buráku & $(-)$ & *buráku & hиесо \\
\hline lonká & 'ronká & $(-)$ & *ronká & roncar \\
\hline
\end{tabular}

La protoconsonante *k se conserva idéntica en las tres lenguas comparadas en todas las posiciones posibles de palabra: en posición inicial ante vocal (*kaỉ); en posición intervocálica (*makáku); y en posición intermedia precedida de consonante nasal (*ronká).

Este último contexto merece una mención especial. Riemer 1779 recoge la forma 'lunga' para el rubro roncar. Esto indica que, en saramaca, al igual que se ha mencionado para los casos de $*$ p y $* \mathrm{t}$, la protoconsonante $* \mathrm{k}$ puede tener facultativamente como reflejo un segmento sonoro, en este caso / g /, cuando está precedida de una consonante nasal.

Este fenómeno puede ser encontrado en otros rubros tanto de origen portugués como de otras lenguas.

$\begin{array}{ll}\text { fingá } & \text { < port. fincar 'hincar, clavar, meter' } \\ \text { diíngi } & \text { < ing. drink 'beber' } \\ \text { síngi } & \text { <ing. sink 'hundirse' } \\ \text { paánga } & \text { < ing. plank 'tablón' } \\ \text { tíngi } & \text { < ing. stink 'heder' } \\ \text { kóng } \sim \text { kónku }<\text { or. desc. 'traicionar, degradar a alguien' }\end{array}$

b.
$/ \mathrm{t} \int /$
/ k /
/ k /
t fumá
'kimá
kemá
*kemá
quemar

La protoconsonante se realiza como una africada alveopalatal cuando está seguida de la protovocal $*$ i , pero en posición inicial de palabra. El término tfumá proviene de la protoforma *t $t$ imá, la cual es recogida como 'tchima' en Riemer 1779. Se trata de un fenómeno de palatalización de la consonante velar propiciado por la presencia de una vocal anterior. El cambio de la vocal / i / > / u / ocurre luego, presumiblemente por influencia de la consonante bilabial / m / (cf. Portilla 2007).

El fenómeno de palatalización de una *k, en posición inicial de palabra ante una protovocal anterior, ocurre también en rubros de origen inglés y provenientes de otras lenguas, como se nota en los ejemplos citados a continuación:
t fái <*kjari < ing. carry 'llevar, cargar'49

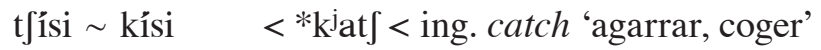
t féni <*keín <ing. cane 'caña de azúcar'
paatjítfi < parakíst < ing. parakeet 'perico'
t fína $\sim$ kína < or. desc. 'tabú, alergia'
lémít $\int \mathrm{i} \sim$ lémíki < or. desc. ‘árbol de limón’ 


\section{6. $* \mathbf{g}$}

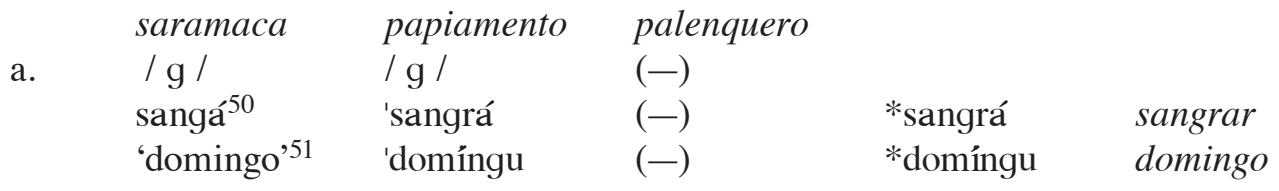

En posición intermedia de palabra, la protoconsonante $* \mathrm{~g}$ se mantiene igual en saramaca y papiamento cuando está precedida por una consonante nasal.

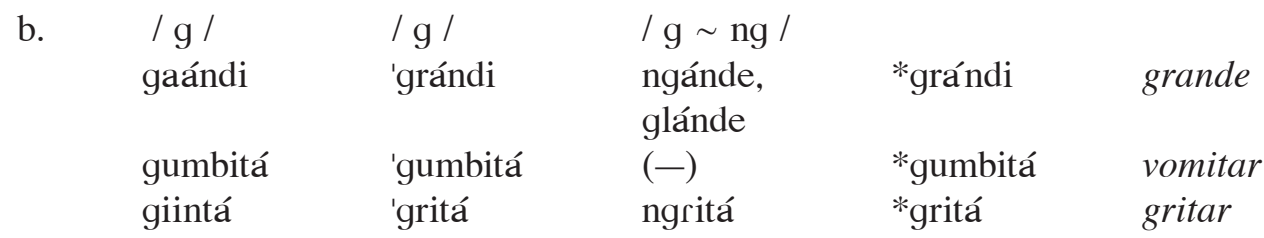

En posición inicial de palabra, la protoconsonante *g se conserva idéntica en saramaca y en papiamento, mientras que en palenquero ocurre una alternancia entre una oclusiva velar sonora y una oclusiva velar prenasalizada ${ }^{52}$. Esta alternancia es semejante a la descrita para la protoconsonante $* \mathrm{~d}$ (cf. 3.4.b).

$\begin{array}{lllll}\text { c. } \quad / \mathrm{g} \sim \mathrm{k} / & / \mathrm{g} / & / \mathrm{g} / & & \\ \begin{array}{l}\text { feegá, } \\ \text { feigá }\end{array} & \text { 'fregá } & \text { fregá } & \text { *fregá } & \text { fregar } \\ \text { papakái } & \text { 'papagái } & \text { (papagád3o) } & \text { *papagái }{ }^{53} & \text { papagayo } \\ \text { paká } & \text { 'pagá } & \text { pagá } & \text { *pagá } & \text { pagar }\end{array}$

En saramaca, la protoconsonante $* \mathrm{~g}$ se realiza o bien como una velar sorda o bien como una velar sonora en posición intervocálica. Esta alternancia en la sonoridad ocurre ya en el siglo XVIII. Riemer 1779 presenta, con el significado del rubro fregar (reiben), las siguientes formas: 'frigá, od. friká'. Igualmente, Riemer 1779 recoge las formas 'pakka' pagar, con una consonante velar sorda, y 'pagamentu' deuda, con una velar sorda. Actualmente, el SIL ofrece este último rubro con una velar sorda: pakaméntu dádiva ${ }^{54}$.

La alternancia en la sonorización de los reflejos de una protoconsonante *g también ocurre en términos de origen inglés.

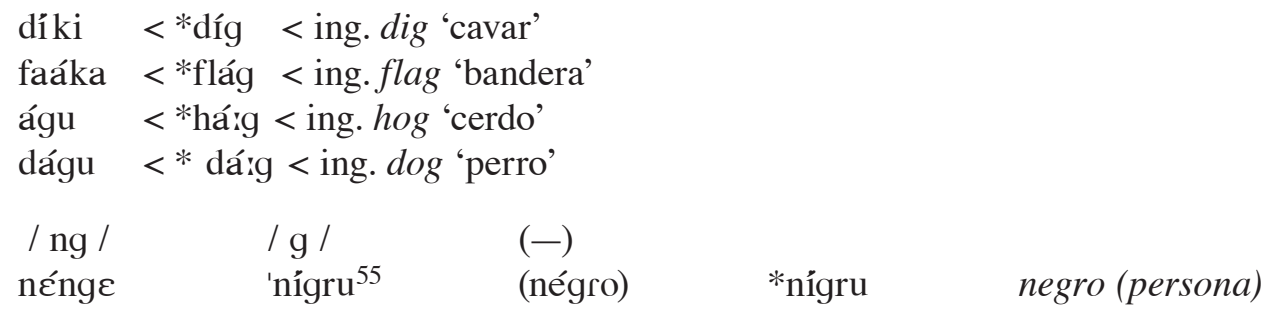

También, en posición intermedia de palabra, la protoconsonante *g se realiza como una velar sonora prenasalizada en saramaca, al parecer cuando existe una consonante nasal en la sílaba anterior. En papiamento, se mantiene como una velar sonora simple. 
En el ejemplo anterior, en saramaca, la derivación del rubro correspondiente a negro es la siguiente: *nígru $>$ *nígri $>$ níngri $(1779)>*^{*}$ níngi $>$ *nínge $>$ nénge ${ }^{56}$. Otros ejemplos en los que ocurre este cambio en saramaca son los siguientes:

$$
\begin{aligned}
& \text { mángu < 'mangru' }(1779)<* \text { magru < port. magro 'delgado' } \\
& \text { bíngo < 'bingo' }(1779)<* \text { mbígu < port. umbigo 'ombligo' } \\
& \text { niingá < 'ninga' }(1779)<* \text { negá < port. negar 'negar' }
\end{aligned}
$$

En saramaca, este fenómeno de prenasalización ha sido descrito también para la protoconsonante $* \mathrm{~d}$ en un contexto semejante (cf. 3.4. d).

En papiamento, este mismo fenómeno aparece también en un rubro. Sin embargo, este proviene del español y no del portugués, según las reglas de derivación de la protolengua para la vocal $* \mathrm{e}^{57}$.

$$
\text { 'nengá < esp. negar }
$$

\section{7. $* \mathrm{t} \int$}

$\begin{array}{lllll}\text { saramaca } & \text { papiamento } & \text { palenquero } & & \\ / \mathrm{t} \int / & / \mathrm{t} \int / & / \mathrm{t} \int / & & \\ \mathrm{t} \text { fúmbu } & \text { 'tfúmbu, } & (-) & * t \text { tfúmbu } & \text { plomo } \\ & \text { 'tfúmbo } & & & \\ \text { tfupá } & \text { 'tfupá } & \text { tfupá } & \text { *tfupá } & \text { chupar } \\ \text { bítfu } & \text { 'bítfi } & \text { (ngusáso) } & \text { *bítfu } & \text { gusano }\end{array}$

La protoconsonante $* \mathrm{t} \int$ se conserva idéntica en saramaca, papiamento y palenquero en posición inicial de palabra y en posición intervocálica, que son las únicas posiciones posibles en las que aparece dicho segmento.

Otros ejemplos en los que aparecen reflejos de esta protoconsonante en saramaca son los siguientes:

$$
\begin{array}{ll}
\text { tfúba } & <\text { port. chuva 'lluvia' } \\
\text { matfáu } & <\text { port. machado 'hacha'59 } \\
\text { latfá } & <\text { port. rachar 'rajar' } \\
\text { fitfá } & <\text { port. fechar 'tupirse, guiñar (el ojo)' } 60
\end{array}
$$

En saramaca, también parece ocurrir una alternancia de sonoridad en los reflejos de la protoconsonante $* \mathrm{t} \int$. Así, por ejemplo, Riemer 1779 recoge la forma 'djumbu' plomo, con una consonante sonora / d 3 /. Igualmente, otros rubros del saramaca presentan un reflejo irregular respecto del portugués. Lamentablemente, no se encuentran cognados de estos términos ni en papiamento ni en palenquero.

$$
\begin{array}{ll}
\text { pindzá } & <\text { port. pinchar 'pinchar' } \\
\text { mandzá } & <\text { port. manchar 'pinchar' }
\end{array}
$$

Este cambio está determinado por la presencia de una consonante nasal sonora antes del segmento africado. Este fenómeno de sonorización es igual al descrito anteriormente para las protoconsonantes $* \mathrm{p},{ }^{*} \mathrm{t},{ }^{*} \mathrm{k}$. 
3.8. $*_{\mathbf{f}}$

a. $\quad / \mathrm{f} /$

saramaca papiamento palenquero

\begin{tabular}{|c|c|c|c|c|}
\hline fuúta & 'frúta & $\begin{array}{l}\text { frúta } \\
\text { flúta }\end{array}$ & *frúta & fruta \\
\hline $\begin{array}{l}\text { feegá, } \\
\text { feigá }\end{array}$ & 'fregá & fregá & *fregá & fregar \\
\hline foló 61 & ('flór) $^{62}$ & fló & *flór & flor \\
\hline
\end{tabular}

La protoconsonante $*_{\mathrm{f}}$ se conserva idéntica en las tres lenguas comparadas en todos los contextos posibles.

Otros ejemplos en los que aparece este segmento en saramaca son los siguientes:

fáka <*fáka < port. faka 'cuchillo'

félu <*féru < port. ferro 'metal, herramienta' 63

fiká <*fiká < port. ficar 'quedarse, permanecer'

fỉnu <*fỉnu < port. fino 'delgado'

fitfá <*fitfá < port. fechar 'tupirse, guiñar (el ojo)'

fulá <*furá < port. furar 'horadar, agujerear'

En papiamento, otros ejemplos de un seguro origen portugués donde aparecen reflejos de este protosegmento son los siguientes:

fru'mỉnga < <frumíga < port. formiga 'hormiga' 64

'fórsa $\quad<$ *órsa < port. força 'fuerza'

'fésta $\quad<*$ fésta $<$ port. festa 'festa'

\section{9. $* *_{\mathbf{v}}$}

saramaca papiamento palenquero

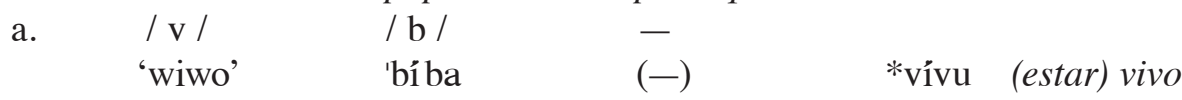

En papiamento, el cambio ${ }^{*} \mathrm{u}>$ a en rubros de origen portugués parece estar condicionado por la presencia de una consonante bilabial en la palabra. Se trata, pues, de un fenómeno de disimilación del rasgo de redondeamiento. En rubros de origen hispánico, por otra parte, este cambio parece deberse más bien a una asimilación a la vocal de la sílaba anterior.

$\begin{array}{ll}\text { 'bỉna } & <\text { port. vinho 'vino' } \\ \text { 'kúrpa } & <\text { port. corpo 'cuerpo' } \\ \text { 'ána } & <\text { esp. año 'año' } \\ \text { 'brása } & <\text { esp. brazo 'brazo' } \\ \text { 'dána }<\text { esp. daño 'daño' } \\ \text { 'klába }<\text { esp. clavo 'clavo' }\end{array}$

Por otro lado, el segmento $*_{\mathrm{v}}$ no parece haber sido muy frecuente en la protolengua. De hecho, solamente el saramaca presenta algunos pocos rubros seguros que atestiguan la presencia de este segmento. 
véntu <*ventu < port. vento 'viento'

avó < <avó < port. avô, avó 'abuelo o abuela'

Riemer 1779 representa estas mismas formas con el grafema 'w'.

$\begin{array}{lll}\text { Riemer } 1779 & \text { Forma actual } & \text { Portugués } \\ \text { 'wintu' } & \text { véntu } & \text { vento 'viento' } \\ \text { 'awwò' } & \text { avó } & \text { avô, avó 'abuelo o abuela' }\end{array}$

Al igual que en papiamento, la mayor de los rubros que contienen el segmento / v / en portugués tienen como reflejo la consonante / b / en saramaca. Por ello, es muy probable que el cambio $*_{\mathrm{v}}>$ b ocurriera ya en el protopidgin mismo. Así, los datos disponibles obligan a postular una protoconsonante $*$ b para la mayor parte de los rubros que presentan la consonante / v / en portugués.

$\begin{array}{lll}\text { saramaca } & \text { papiamento } & \\ \text { / b / } & \text { / b / } & <* \text { b } \\ \text { katíbo } & \text { 'katíbu, 'katíbo } & \text { *katíbu < port. cativo 'esclavo'65 } \\ \text { biá66 } & \text { 'birá } & \text { *birá < port. virar 'volverse'67 }\end{array}$

Otros rubros del saramaca que presentan el segmento / b / como reflejo del cambio port. / v / > protopidgin $* \mathrm{~b}$ son los siguientes:

tfúba $<* t$ úba < port. chuva 'lluvia'

buwá <*buá < port. voar 'volar'

De acuerdo con los datos que ofrece el saramaca, el cambio port. / v / > protopidgin *b parece ocurrir principalmente cuando este segmento se halla en sílaba inacentuada (*katíbo, *biá, *tfúba). Por otro lado, la conservación de port. / v / > protopidgin *v se da en sílaba acentuada (*vívu, *véntu, *avó).

Como se ha dicho, en papiamento, el cambio $*_{\mathrm{v}}>\mathrm{b}$ ocurre en todos los casos. Otro ejemplo de indiscutible origen portugués que presentan este cambio en esta lengua es el siguiente:

'bỉn < *bỉn < port. vem 'venir'68

\subsection{0. $*_{\mathrm{S}}$}

\begin{tabular}{|c|c|c|c|c|}
\hline \multirow{6}{*}{$\begin{array}{l}\text { saramaca } \\
\text { a. } \quad \text { / s / } \\
\text { sábi } \\
\text { súndzu } \\
\text { sendé } \\
\text { sindó }\end{array}$} & papiamento & palenquero & & \\
\hline & / s / & / s / & & \\
\hline & 'sábi, 'sá & sá be & *sábi & saber \\
\hline & 'sufi & (súsio) & *súzu & sucio \\
\hline & 'sendé & $(-)$ & *sendé & encender \\
\hline & 'sintá & $\begin{array}{l}\text { sendá, } \\
\text { sentá }\end{array}$ & *sentá & sentarse \\
\hline sintỉ & 'sintí & $\begin{array}{l}\text { sendí, } \\
\text { sindí }\end{array}$ & *sentỉ & sentir \\
\hline suján & 'sopá & $(-)$ & *sojá & soñar \\
\hline pasá & 'pasá & pasá & *pasá & pasar \\
\hline
\end{tabular}




$\begin{array}{lllll}\text { kákísa } & \text { 'káska } & (-) & \text { *káska } & \text { corteza } \\ \text { sugúu } & \text { 'sukú, skur } & \text { (ekúro) } & \text { *skúru } & \text { oscuro } \\ \text { alísi } & \text { 'arós } & \text { aló } & \text { *arós } & \text { arroz }\end{array}$

La protoconsonante *s se conserva idéntica en las tres lenguas comparadas en posición inicial de palabra ante vocal (*sábi) y en posición intervocálica (*pasá). Ante consonante, esta protoconsonante se conserva idéntica en saramaca y en papiamento (*káska, *skúru). En posición final de palabra, también se conserva en estas dos lenguas, pero se pierde en palenquero (*arós).

$\begin{array}{lllll}\text { b. } \quad \text { / z / } & (-) & & \\ \text { lánza } & \text { 'lánsa } & (-) & \text { *lánsa } & \text { lanza }^{69} \\ \text { 'lensu'70 } & \text { 'lénsu } & (-) & \text { *lensu } & \text { pañuelo }\end{array}$

La protoconsonante $*_{\mathrm{s}}$ se sonoriza en saramaca cuando está precedida por una consonante nasal. Este fenómeno de sonorización de una consonante sorda cuando va seguida de una nasal ha sido mencionado antes también para las protoconsonantes * $\mathrm{p}$, ${ }^{*} \mathrm{t},{ }^{*} \mathrm{k}$, $* \mathrm{t}$.

Además, se debe mencionar que, en esta lengua, en algunos casos se da una alternancia entre los fonemas / s / y / z /.

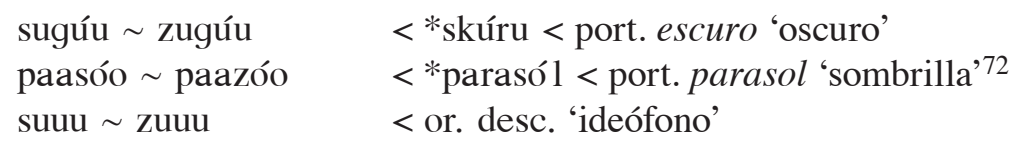

\subsection{1. $*_{\mathrm{Z}}$}

saramaca papiamento palenquero
a. $\quad / \mathrm{nz} /$
| z /
$(-)$
'lízu
$(-)$
*lízu
liso

Riemer 1779 presenta dos formas para este rubro: 'linsu' y 'liso'.

En saramaca, la aparición de una consonante nasal intrusa ante la protoconsonante ${ }^{*} \mathrm{z}$ puede observarse también en el siguiente caso:

hánsa < *áza < port. asa / 'azə / 'ala'

En saramaca, también parece ocurrir una confusión entre las protocononantes $*_{z}$ y $*_{3}$. Por ello, los siguientes rubros presentan una realización inesperada de acuerdo con el étimo portugués del cual presumiblemente provienen.

sỉndja <*sỉnza cf. port. cinza / 'sĩ zə / 'ceniza'

zuntá <*zuntá cf. port. juntar / zữtar / 'juntar'

zúntu <*zúntu cf. port. junto / 'zũtu / 'junto'

Riemer 1779 recoge también un ejemplo de la variación entre las protoconsonantes mencionadas en el caso del rubro sucio: ‘sunju, od. sunsu' i.e. *súnzu *súnzu.

En papiamento, la protoconsonante $*_{\mathrm{z}}$ aparece en otros pocos rubros:

'úzu <*úzu < port. uso / 'uzu / 'uso'

'uzá <*uzá < port. usar / 'uzar / 'usar' 


\subsection{2. *}

$\begin{array}{lllll}\text { saramaca } & \text { papiamento } & \text { palenquero } & & \\ \text { / s / } & / \int / & (-) & & \\ \text { pusá } & \text { 'pufá } & (\text { puhá) } & \text { *pufá } & \text { empujar } \\ \text { olóísi } & \text { o'ló } \int \mathrm{i} & (-) & \text { *olófi } & \text { reloj }^{73}\end{array}$

En saramaca, el cambio $* \int>\mathrm{s}$ parece haberse consolidado apenas después del siglo XVIII. En muchos casos, Riemer 1779 presenta una alternancia entre los segmentos / f / (ortográficamente 'sh') y / s / (ortográficamente 's') respecto de las formas actuales del saramaca, tanto en palabras de origen portugués como inglés.

\begin{tabular}{|c|c|}
\hline pusá & 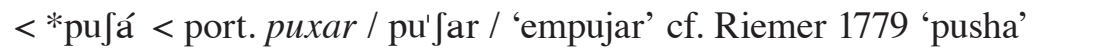 \\
\hline disá & < *difá < port. deixar / dei'Jar / 'dejar' cf. Riemer 1779 'disha' \\
\hline básu & < *bá Ju < port. baixo / 'baifu / 'bajo' cf. Riemer 1779 'bâsu' \\
\hline baziá & < *baJiá < port. baixar / bai'Jar / 'dejar' cf. Riemer 1779 'bashia' \\
\hline pasá & < *pasá < port. passar / pa'sar / 'pasar' cf. Riemer 1779 'pashà' \\
\hline & 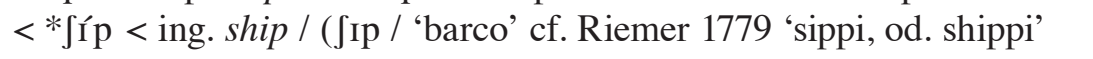 \\
\hline & ing. cassava / kə'savə / 'yuca' cf. Riemer 1779 'cashaba' \\
\hline & louse / 'laus / 'piojo' cf. Riemer 1779 'loshu' \\
\hline
\end{tabular}

En papiamento, hay otro rubro de un claro origen portugués que presenta el reflejo regular del protofonema $* \int$ :

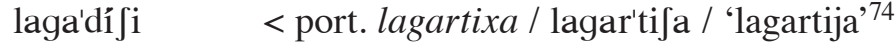

\subsection{3. $*_{3}$}

$\begin{array}{cllll}\text { saramaca } & \text { papiamento } & \text { palenquero } & & \\ \text { a. } & / \mathrm{nd} 3 / & / \int / & (-) & \\ \text { súndzu } & \text { 'súfi } & \text { (súsio) } & \text { *súzu } & \text { sucio }^{75}\end{array}$

Lamentablemente, no es posible hallar más cognados con reflejos de este en las lenguas comparadas. Incluso, tampoco en el caso del rubro sucio, hay una completa seguridad de que la forma del papiamento provenga del portugués y no del español.

Así, la derivación desde el portugués de este término en papiamento sería la siguiente:

Port. sujo / 'suzu / > *súzu > *sú $\int u$ > 'sú $\int i^{76}$

En esta misma lengua, hay dos términos de un supuesto origen portugués que ejemplifican la realización de la protoconsonante $*_{3}$ como un segmento fricativo sordo:

$\begin{array}{ll}\text { ku'rá } \int \mathrm{i} & <\text { port. coragem / kor'zẽ i / 'coraje' } \\ \text { ma'sá } \int \mathrm{i} & <\text { port. massagem / ma'sazẽ i / 'masaje' }\end{array}$

Por otra parte, en saramaca la derivación del término sucio es la siguiente:

Port. sujo / 'suzu / > *súzu > súnzu > súndzu

En saramaca, pueden encontrarse otros tres rubros de claro origen portugués que ilustran la realización de la protoconsonante $*_{3}$ como un segmento africado sonoro:

miindzá < *mizá < port. mijar / 'mizar / 'mear'77 
alándza < *aránza < port. laranja/ la'rãza / 'naranja'

makudzá < *markuzá < port. maracujá / maraku'za / 'maracuyá'78

dzurá <*3urá < port. jurar/ zu'rar / 'jurar'

3.14. *m

\begin{tabular}{|c|c|c|c|c|}
\hline saramaca & papiamento & palenquero & & \\
\hline mái & 'mái & máe & *má i & madre ${ }^{79}$ \\
\hline múndu & $\begin{array}{l}\text { 'múndu, } \\
\text { 'múndo }\end{array}$ & múndo & *múndu & mundo \\
\hline $\begin{array}{l}\text { *mulé80 } \\
\text { duumí }\end{array}$ & $\begin{array}{l}\text { 'muri } \\
\text { 'drumí }\end{array}$ & $\begin{array}{l}\text { murí81 } \\
\text { drumí, }\end{array}$ & $\begin{array}{l}\text { *muré } \\
\text { *drumí }\end{array}$ & $\begin{array}{l}\text { morir } \\
\text { dormir }\end{array}$ \\
\hline puúma & 'plúma & plúma & *plúma & pluma \\
\hline komé & 'komé & $\begin{array}{l}\text { kumé, } \\
\text { komé }\end{array}$ & *komé & comer \\
\hline $\begin{array}{l}\text { tfumá } \\
\text { makáku }\end{array}$ & $\begin{array}{l}\text { 'kimá } \\
\text { ma'káku, } \\
\text { ma'ká ko }\end{array}$ & $\begin{array}{l}\text { kemá } \\
\text { (móno) }\end{array}$ & $\begin{array}{l}\text { *kemá } \\
\text { *makáku }\end{array}$ & $\begin{array}{l}\text { quemar } \\
\text { mono }\end{array}$ \\
\hline $\begin{array}{l}\text { límbo, } \\
\text { límpo }\end{array}$ & 'límpi & $\begin{array}{l}\text { 'límpio, } \\
\text { límpiu) }\end{array}$ & *límpu & limpio \\
\hline kómpe & 'kómpai & (amígo) & *kómpai & amigo \\
\hline lembé & 'lembé & $(-)$ & *lembé & lamer \\
\hline
\end{tabular}

La protoconsonante $* \mathrm{~m}$ se conserva de manera idéntica en posición inicial de palabra (*mái), en posición intervocálica (*drumí) y ante consonante (*límpu).

Es importante señalar que, en saramaca, ocasionalmente la consonante etimológica $/ \mathrm{m} /$ del portugués, y también de otras lenguas, da como resultado la consonante prenasalizada / mb /. Algunos ejemplos de este cambio son los siguientes:

gumbitá < *gumbitá < port. gomitar 'vomitar'82

mbỉi $<*$ míl $<$ ing. mill 'molino"83

mbéi <*mé:k < ing. make 'hacer" ${ }^{94}$

tombombỉ i < hol. automobiel 'automóvil' 85

mumúu mumbúú < or. desc.'tipo de palmera'

Este mismo cambio ocurre en papiamento, aunque solo se da en este caso:

'gumbitá < *gumbitá < port. gomitar 'vomitar'

3.15. $* \mathbf{n}$

saramaca papiamento palenquero

a. $/ \mathrm{n} /$

/ n /

/ $\mathrm{n} /$

na na (en)

nénge 'nígru

(négro)

'bunîta'86

'buníta

(bonito)
*na
*nígru
*buníta

en

negro (persona)

bonito 


\begin{tabular}{|c|c|c|c|c|}
\hline gaándi & 'grándi & $\begin{array}{l}\text { ngánde, } \\
\text { glánde }\end{array}$ & *grándi & grande \\
\hline $\begin{array}{l}\text { múndu } \\
\text { 'múndo }\end{array}$ & 'múndu, & múndo & *múndo & mundo \\
\hline dendá 87 & 'drentá & lendrá & *dentrá & entrar \\
\hline sendé & 'sende' & $(-)$ & *sendé & encender \\
\hline sindó & 'sintá & $\begin{array}{l}\text { sendá, } \\
\text { sentá }\end{array}$ & *sentá & sentarse \\
\hline sintí & 'sintí & $\begin{array}{l}\text { sendí, } \\
\text { sindí }\end{array}$ & $*_{\text {sentí }}$ & sentir \\
\hline kondá & 'kontá & (kuénda) & *kontá & contar \\
\hline lonká & 'ronká & $(-)$ & *ronká & roncar \\
\hline$\left(\mathrm{d} \varepsilon^{\prime}\right)$ & 'tỉn & tén & *tén & tener \\
\hline búnu & 'bón & (búeno) & *bón & bueno \\
\hline máun & 'man & (máno) & *máun & mano \\
\hline (baáa) & ru'mán & numáno & *rumáun 88 & hermano \\
\hline amaján & ma'ján & (maaná) $^{89}$ & *amájan & mañana \\
\hline
\end{tabular}

En las tres lengua comparadas, la protoconsonante *n se conserva idéntica en todas las posiciones posibles de la palabra: en posición inicial (*na), intervocálica (*buníta), preconsonántica (*dentrá) y final (*tén).

En saramaca, la aparición de la consonante / n / en los rubros mano y mañana es producto de un cambio posterior en saramaca. Esta consonante nasal aparece en las palabras terminadas en vocal cuya sílaba final contiene una consonante nasal (cf. 4.2.c).

Así, las palabras mano y mañana habrían sufrido las siguientes derivaciones desde el protopidgin:

mão $\sim$ man / (mão (man / > *máun > mau (1779) > máun.

amanhã $\sim$ amanhan / ama'jã $\sim$ ama'jan / > * amaján $>$ amaija (1779) > amaján.

\subsection{6. *n}

$\begin{array}{lllll}\text { saramaca } & \text { papiamento } & \text { palenquero } & & \\ \text { / j / } & \text { / j / } & (-) & & \\ \text { húnan } & \text { 'húna } & (-) & \text { *úna } & \text { garra } \\ \text { suján } & \text { 'sojá } & (-) & \text { *sojá } & \text { soñar } \\ \text { amaján } & \text { ma'ján } & \text { (maaná) } & \text { *amánan } & \text { mañana } \\ \text { gaján } & \text { 'gajá } & (-) & * \text { gajá90 } & \text { engañar }\end{array}$

La protoconsonante *n se conserva idéntica en saramaca y papiamento.

Otros ejemplos con el reflejo de esta protoconsonante en sararamaca son los siguientes:

panán < *paná < port. apanhar 'agarrar, sostener'

sipajólu <*spajól < port. espanhol 'español'

En papiamento, otros rubros de indudable origen portugués que presentan el reflejo regular de esta protoconsonante son los siguientes:

'galỉna <*galína < port. galinha 'gallina'

'lína $<$ *lína < port. linha 'cordel'

'supína <*spína < port. espiña 'espina' 
3.17. $* 1$

$\begin{array}{lllll}\text { saramaca } & \text { papiamento } & \text { palenquero } & & \\ \text { a. } & / 1 / & \text { / / } & & \\ \text { línzo } & \text { 'lízu } & (-) & \text { *lízu } & \text { liso } \\ \text { lánza } & \text { 'lánsa } & (-) & \text { *lánsa } & \text { lanza } \\ \text { 'lensu' } & \text { 'lénsu } & (-) & \text { *lensu } & \text { pañuelo } \\ \text { lembé } & \text { 'lembé } & (-) & \text { *lembé } & \text { lamer } \\ \text { límbo, } & \text { 'límpi } & \text { 'límpio, } & \text { *límpu } & \text { limpio } \\ \text { límpo } & & \text { límpiu) } & & \\ \text { gulí } & \text { 'gulí } & (-) & \text { *gulí } & \text { engullir } \\ \text { (a) } & \text { 'éle } & \text { éli, éle } & \text { *éli } & \text { él }{ }^{91} \\ \text { alá } & \text { ('éi) } & \text { lá } & \text { *alá } & \text { allá }\end{array}$

La protoconsonante *1 se conserva idéntica en las tres lenguas en posición inicial de palabra (*lízu) y en posición intervocálica (*gulí). Según los datos que ofrece Riemer 1779, ocasionalmente, en saramaca, los reflejos de esta protoconsonante se confundían con aquellos de la protoconsonante *r en esta posición silábica. Esto se nota en el siguiente ejemplo:

$\begin{array}{lll}\text { Riemer } 1779 & \text { Forma actual } & \text { Portugués } \\ \text { 'aneru' } & \text { andélu } & \text { anelo 'anillo' }\end{array}$

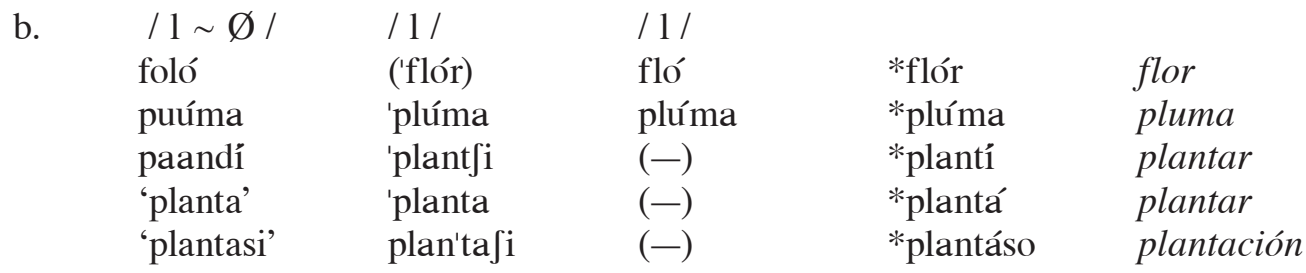

En posición tautosilábica con una obstruyente (*plúma), la protoconsonante *1 se conserva idéntica en papiamento y en palenquero. En saramaca, esta desaparece actualmente en la mayor parte de los casos, aunque se conserva, al parecer, cuando la palabra es monosilábica.

Como muestran los ejemplos, en el siglo XVIII, la regla de elisión de la protoconsonante *1 todavía no había iniciado en saramaca, aunque se nota ya una confusión de los reflejos de la este segmento con la protoconsonante *r (cf. 3.15).

$\begin{array}{lll}\text { Riemer } 1779 & \text { Forma actual } & \text { Portugués } \\ \text { 'floli, flolo, froro' } & \text { foló } & \text { flor 'flor' } \\ \text { 'pluma' } & \text { puúma } & \text { pluma 'pluma' } \\ \text { 'planta, pranta' } & - & \text { plantar'plantar' }\end{array}$

Este fenómeno ocurre también con palabras de origen inglés.

\begin{tabular}{|c|c|c|c|}
\hline $\begin{array}{l}\text { Riemer } 1779 \\
\text { 'blo, bro' } \\
\text { 'blakka, brakka' } \\
\text { 'kroshu, kloshu' koósu }\end{array}$ & $\begin{array}{l}\text { Forma actual } \\
\text { bəó } \\
\text { baáka }\end{array}$ & $\begin{array}{l}\text { Inglés } \\
\text { blow } \\
\text { black } \\
\text { clothes }\end{array}$ & $\begin{array}{l}\text { 'soplar, respirar' } \\
\text { 'negro, azul' } \\
\text { 'ropa' }\end{array}$ \\
\hline $\begin{array}{l}\text { / } 1 \text { / } \\
\text { sipanólu }\end{array}$ & $\begin{array}{l}(-) \\
(-)\end{array}$ & *spajól & español \\
\hline
\end{tabular}


En posición final de palabra, la protoconsonante $* 1$ se conserva en saramaca, pero desaparece en papiamento. Lamentablemente, no se cuenta con otros ejemplos para este haz de correspondencias.

\subsection{8. $* \mathbf{r}$}

$\begin{array}{cllll}\text { saramaca } & \text { papiamento } & \text { palenquero } & & \\ \text { a. } & \text { / r / } & / \mathrm{f} \sim 1 / & & \\ \text { líba } & \text { 'ríba } & \text { ríba } & \text { *ríba } & \text { sobre, encima de } \\ \text { lábu } & \text { 'rábu, } & \text { lábo } & \text { *ábu } & \text { rabo } \\ & \text { 'rábo } & & & \\ \text { lío } & \text { 'ríu } & \text { (rỉo) } & \text { *ríu } & \text { río } \\ \text { lonká } & \text { 'ronká } & (-) & \text { *ronká } & \text { roncar }\end{array}$

En papiamento, la protoconsonante $*$ r se conserva idéntica en todas las posiciones posibles de la palabra.

En saramaca, esta protoconsonante se convierte siempre en una lateral en posición inicial de palabra (*rỉba). Este cambio parece haber aparecido ya en el siglo XVIII, ya que Riemer 1779 presenta los rubros que contienen reflejos de esta protoconsonante siempre con la consonante lateral en esta posición.

$\begin{array}{ll}\text { Riemer } 1779 & \text { Forma actual } \\ \text { 'liba' } & \text { líba } \\ \text { 'lio' } & \text { lío } \\ \text { 'labo' } & \text { lábu } \\ \text { 'lolà' } & \text { lolá } \\ \text { 'lalá' } & \text { lalá } \\ \text { 'luluntu' } & -\end{array}$

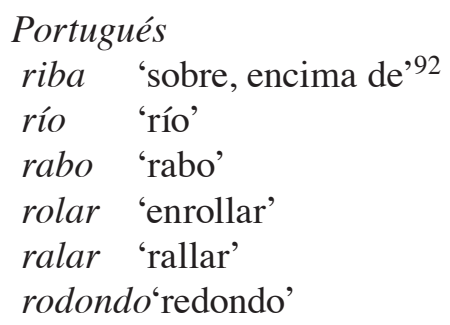

En palenquero, la protoconsonante *1 se realiza o bien como una vibrante simple cuando va seguida de la vocal / i / o bien como una lateral ante las demás vocales (cf. otros ejemplos infra).

$\begin{array}{lllll}\text { b. / / } ~ & \text { / r / } ~ & \text { / / } & \\ \text { balí, baí } & \text { 'barí } & \text { (balé) } & \text { *barí } & \text { barrer } \\ \text { palí, paí } & \text { 'barí } & \text { parí } & \text { *parí } & \text { parir } 93 \\ \text { (láfu) } & \text { 'arí } & \text { arí } & \text { *arí } & \text { reír } \\ \text { baíka } & \text { ba'ríka } & \text { baríka } & \text { *baríka } & \text { estómago, barriga } \\ \text { baáku } & \text { 'buráku } & (-) & \text { *buráku } & \text { hueco } \\ \text { kulá } & \text { 'kurá } & \text { kulá } & \text { *kurá } & \text { curar } \\ \text { kulé } & \text { 'kurí } & \text { kulé } & \text { *kuré } & \text { correr } \\ \text { bulíki } & \text { bu'ríku, } & \text { (búlo) } & \text { *buríku } & \text { burro, borrico } \\ & \text { bu'ríko } & & & \\ \text { alísi } & \text { 'arós } & \text { aló } & \text { *arós } & \text { arroz } \\ \text { téla } & \text { 'téra } & \text { (tiéla) } & \text { *téra } & \text { tierra }\end{array}$


En posición intervocálica, la protoconsonante $*_{\mathrm{r}}^{\mathrm{r}}$ se realiza como una lateral o desaparece en saramaca. Los datos recogidos por Riemer 1779 muestran que, en esta posición silábica, el cambio *r $>r \sim 1>\varnothing$ se inició en el siglo XVIII.

Riemer 1779
'bâli, bari'
'pali'
'barika'
'blaku'
'kula'
'kuleh'
'alîsi'
'téla'

Forma actuá, baí
balí, paí
palík
baíka
baáku
kulá
kulé
alísi
téla

$\begin{array}{ll}\begin{array}{l}\text { Portugués } \\ \text { barrer }\end{array} & \\ \text { parir } & \text { 'barrer' } \\ \text { barriga } & \text { 'parir' } \\ \text { buraco } & \text { 'barriga' } \\ \text { curar } & \text { 'curar' } \\ \text { correr } & \text { 'correr' } \\ \text { arroz } & \text { 'arroz' } \\ \text { terra } & \text { 'tierra' }\end{array}$

c.

\begin{tabular}{|c|c|c|c|c|}
\hline $\begin{array}{c}\varnothing \\
\text { duumí }\end{array}$ & $\begin{array}{l}\text { / r / } \\
\text { 'drumí }\end{array}$ & $\begin{array}{l}\text { / f 1/ } \\
\text { drumí, }\end{array}$ & *drumí & dormir \\
\hline gaándi & 'grándi & $\begin{array}{l}\text { ndrumí } \\
\text { ngánde, } \\
\text { qlándee }\end{array}$ & *grándi & grande \\
\hline fuúta & 'frúta & $\begin{array}{l}\text { frúta } \\
\text { flúta }\end{array}$ & *frúta & fruta \\
\hline $\begin{array}{l}\text { feegá, } \\
\text { feigá }\end{array}$ & 'fregá & fregá & *fregá & fregar \\
\hline tiípa & 'trípa & $(-)$ & *trípa & intestinos \\
\hline nénge & 'nígru & (négro) & *nígru & negro (persona) \\
\hline sangá & 'sangrá & $(-)$ & *sangrá & sangrar \\
\hline
\end{tabular}

En posición tautosilábica con una consonante obstruyente, en saramaca, la protoconsonante siempre desaparece. Este cambio parece haberse consolidado después del siglo XVIII, ya que este no aparece todavía en Riemer 1779.

Riemer 1779
'drummi'
'grandi'
'fruta'
'frigá, friká'
'tripa'
'ningri'
'sangla'

Forma actual
duumí
gaádi
fuúta
feegá, feigá
tiíṕa
néngé
sangá

Portugués
dormir
grande
fruta
fregar
tripa
negro
sangrar

'dormir'
'viejo'
'fruta'
'fregar'
'tripa, intestino'
'negro (persona)'
'sangrar por la nariz'

Sin embargo, los datos de Riemer 1779 muestran que, en algunas ocasiones, ocurría una alternancia $* r>r \sim 1$ en esta posición silábica, como la descrita ya en el 3.18b para los reflejos de esta misma consonante y en $3.17 \mathrm{~b}$ para los reflejos de la protoconsonante $* 1$.

$\begin{array}{lll}\text { Riemer } 1779 & \text { Forma actual } & \text { Portugués } \\ \text { 'sangla' } & \text { sangá } & \text { sangrar 'sangrar por la nariz'94 } \\ \text { 'glunja' } & \text { guunán } & \text { guñir 'murmurar, quejarse'95 }\end{array}$




\subsection{9. $* \mathbf{j}$}

\section{saramaca papiamento palenquero}

a. $\quad / \mathrm{j} /$

$$
\text { bakajáu }
$$

$$
/ \mathrm{j} /
$$

gujába

'saija'96

\begin{tabular}{ll}
\multicolumn{2}{c}{ 'bakijou $(-)$} \\
gu'jába & (guajába) \\
'saja & $(-)$
\end{tabular}

$\begin{array}{ll} & \text { *bakajáu bacalao } \\ \text { *gujába } & \text { guayaba } \\ \text { *sája } & \text { enagua }\end{array}$

En posición intervocálica, la protoconsonante *j se conserva idéntica en saramaca y en papiamento.

Otros rubros donde aparecen reflejos de este protosegmento en saramaca son los siguientes:

agúja < *agúja < port. agulha 'aguja'

mujéc <*mujér < port. mulher 'mujer'97

ójo < *ójo < port. olho 'olho'

kujéc <*kujér < port. colher 'cuchara'98

teéja < *tréja < port. *estrelha 'estrella'99

Es interesante señalar que el segmento $*_{\mathrm{j}}$ de este protopidgin corresponde tanto a la consonante / $K /(l h)$ como a la / j / (i) del portugués estándar, como se nota en los siguientes ejemplos:

\begin{tabular}{lll} 
Forma reconstruida & \multicolumn{2}{l}{ Forma portuguesa } \\
*bakajáu & / baka'Káu / & bacalhao 'bacalao' \\
*agúja & / a'guKa / & agulha 'aguja' \\
*gujába & / go'jaba / & goiaba 'guayaba' \\
*sája & / sa'ja / & saia 'enagua'
\end{tabular}

\section{Consonantes intrusas}

\subsection{Consonantes protéticas}

Tanto el saramaca como el palenquero presentan una tendencia a insertar una paravocal ante vocales en posición inicial de palabra. En saramaca, aparecen las paravocales / j, h / en esta posición, mientras que, en papiamento, lo hace la paravocal / h /.

a. $\quad \varnothing>\mathrm{j}$ en saramaca

$\begin{array}{lllll}\text { saramaca } & \text { papiamento } & \text { palenquero } & \\ \text { jabí } & \text { 'habrí } & \text { abrí } & \text { *abrí abrir } \\ \text { jasá } & \text { 'hasá } & (-) & \text { *asá asar }\end{array}$

b. $\quad \varnothing>\mathrm{h}$ en saramaca

$\begin{array}{lll}\text { saramaca } & \text { papiamento } & \text { palenquero } \\ \text { húnan } & \text { 'húna } & (-)\end{array}$ *úna uña


La introducción de esta paravocal en posición inicial de palabra ocurre sobre todo en rubros de origen inglés. Otros ejemplos de este fenómeno en saramaca son los siguientes:

$$
\begin{aligned}
& \text { hánza < *áza < port. asa 'ala' } \\
& \text { hánsi < *ánts < ing. ant 'hormiga' } \\
& \text { hágu < *́́'g < ing. hog 'cerdo' } \\
& \text { hóni < *́ni < ing. honey 'abeja'100 }
\end{aligned}
$$

En esta lengua, en ciertos rubros, la aparición de este segmento protético es facultativa.

$$
\begin{aligned}
& \text { hákísi á kísi < *á:ks < ing. ask 'pedir, preguntar' } \\
& \text { háma áma < *áma < ing. hammer 'martillo' }
\end{aligned}
$$

c. $\quad \varnothing>\mathrm{h}$ en papiamento

$\begin{array}{lllll}\text { saramaca } & \text { papiamento } & \text { palenquero } & \\ \text { jabí } & \text { 'habrí } & \text { abrí } & \text { *abrí abrir } \\ \text { jasá } & \text { 'hasá } & (-) & \text { *asá cáscara } \\ \text { húnan } & \text { 'húna } & (-) & \text { *úna } & \text { uña } \\ \text { (láfu) } & \text { 'harí } & \text { arí } & \text { *arí } & \text { reír }\end{array}$

En papiamento, este fenómeno ocurre tanto en rubros de origen portugués como español:

'horéja < port. orelha 'oreja'

'harána < port. o esp. araña 'araña'

'hómber < esp. hombre 'hombre'

'holé < esp. oler 'oler'

En esta lengua, la aparición de esta paravocal también es facultativa.

'horéja 'oréja < port. orelha 'oreja'

'holé 'olé < esp. oler 'oler'

En este punto es necesario hacer una referencia a los rubros que presentan el segmento / h / en palenquero. En esta lengua, estos rubros parecen haber mantenido la aspiración original que existía en los étimos de origen hispánico. Como es sabido, en español, el segmento paravocal / h /, representado ortográficamente con la letra $h$, sufrió un proceso de desaparición durante el siglo $\mathrm{XVI}^{101}$. Sin embargo, en algunas hablas predominantemente rurales ${ }^{102}$, este se ha conservado en ciertos rubros, y se ha fundido entonces con el segmento fricativo / x /, representado normalmente con la letra $j$. Por ello, se puede afirmar que, en palenquero, los rubros que presentan el segmento / h / provienen del español y no del protopidgin afroportugués, aunque estos sean cognados de otros rubros del papiamento.

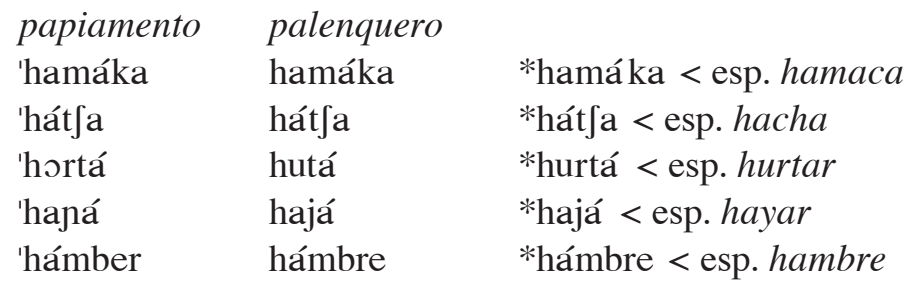




\subsection{Consonantes paragógicas}

a. $\quad \varnothing>$ w/u en saramaca

Es probable que el fenómeno de paragoge sea propiciado por la tendencia de esta lengua a la composición silábica $\mathrm{CV}$.

Por un lado, se inserta la paravocal / w / en rubros de origen portugués con la estructura silábica $\mathrm{Cu}+$ á:

buwá < port. voar 'volar'

suwá < port. suar 'sudar'

Por otro lado, en rubros de origen inglés, se inserta la vocal paragógica / u / cuando se presenta la estructura silábica $\mathrm{C}+\mathrm{w} v^{\text {. }}$

suwámpu < ing. swamp 'pantano'

tuwénti < ing. twenty 'veinte'

b. $\quad \varnothing>\mathrm{n}$ en saramaca

En posición final de palabra, se inserta la consonante nasal / $\mathrm{n}$ / después de una vocal o un diptongo cuando los segmentos van precedidos de una consonante nasal / $\mathrm{m}, \mathrm{n} /$.

$\begin{array}{lllll}\text { saramaca } & \text { papiamento } & \text { palenquero } & & \\ \text { húnan } & \text { 'húja } & (-) & \text { *úja } & \text { garra } \\ \text { suján } & \text { 'sojá } & (-) & \text { *sojá } & \text { soñar } \\ \text { ganán } & \text { 'ganá } & (-) & \text { *gajá } & \text { engañar } \\ \text { máun } & \text { 'man } & \text { (máno) } & \text { *máun } & \text { mano } \\ \text { amaján } & \text { ma'ján } & \text { (maaná) } & \text { *amájan } & \text { mañana }\end{array}$

Otros rubros del saramaca que muestran este fenómeno son los siguientes:

máúnmáun < port. mau + mau 'estar entre la vida y la muerte'103

mamáun < port. mamão 'papaya'

panán < port. apanhar 'sostener, coger'

munán < *muná < *mujá < port. molhar 'mojar'

guján < port. grunhir 'murmurar, quejarse'

Este fenómeno de paragoge parece haber ocurrido en saramaca después del siglo XVIII, ya que no aparece en los datos recogidos por Riemer 1779.

$\begin{array}{lll}\text { Riemer } 1779 & \text { Forma actual } & \text { Portugués } \\ \text { 'mau' } & \text { máun } & \text { mão 'mano, pierna' } \\ \text { 'glunja' } & \text { guunán } & \text { guñir 'murmurar, quejarse' } \\ \text { 'sunja, sonja' } & \text { sunán } & \text { sonhar 'soñar' } \\ \text { 'hunja' } & \text { húnan } & \text { unha 'uña' } \\ \text { 'amaija' } & \text { amanán } & \text { amanhã 'mañana' } \\ \text { 'muija' } & \text { munán } & \text { molhar 'mojar' }\end{array}$




\section{Abreviaturas}

$\begin{array}{ll}\text { esp. } & \text { español } \\ \text { hol. } & \text { holandés } \\ \text { ing. } & \text { inglés } \\ \text { pal. } & \text { palenquero } \\ \text { pap. } & \text { papiamento } \\ \text { port. } & \text { portugués } \\ \text { sar. } & \text { saramaca }\end{array}$

\section{Notas}

1. Las variedades de pidgins y criollos portugueses se extendían por África Occidental (el Golfo de Guinea), África meridional (Angola), África oriental (Madagascar), el sudeste asiático (Birmania, Malasia, Indonesia), el subcontinente indio (incluida Sri Lanka), China y el Oriente Medio (Irán, Iraq y Arabia Saudita) (cf. Smith 1995). Los criollos españoles de las Filipinas tienen su origen también en un pidgin portugués (cf. Whinnom 1965).

2. El origen portugués de estos criollos ha sido ampliamente defendido. Para el caso del saramaca, véanse Perl et al. 1993 y Bickerton 1999. Para el caso del papiamento, véanse Granda 1974 y Maurer 1998a, quienes lo hacen provenir de una variedad importada directamente de África. Goodman 1987, Holm 1989 y McWhorter 1999, por su parte, sostienen que el papiamento proviene de una variedad de pidgin portugués que se utilizaría ya en las plantaciones de judíos sefarditas refugiados, provenientes del nordeste de Brasil a través de Surinam en 1659 y no directamente de África. En defensa del origen portugués del palenquero, véanse Granda 1970, Megenney 1983, Perl 1989a, 1990, Schwegler 1991, 1993, Moñino 2007.

3. Cf. Bartens 1995, Bakker et al. 1995, Kouwenberg y Muysken 1995, Schwegler 1999 y Patiño 2002.

4. El contenido de este apartado aparece de manera idéntica en Portilla 2007. Aquí se reproduce de nuevo porque es indispensable para la justificación científica de la reconstrucción de las consonantes, así como lo fue para la correspondiente reconstrucción de las vocales presentada en el mencionado trabajo anterior.

5. La descripción de la fonología de esta lengua está basada en Taylor 1977, Voorhoeve 1959 y Rountree 1972.

6. La descripción de la fonología de esta lengua está basada en Kouwenberg y Muysken 1995 y Maurer 1998 a.

7. Cf. Schwegler 1998 y Friedemann y Patiño 1983.

8. Schwegler 1998 propone la fonologización de una serie de oclusivas sonoras tensas $/ \cdot b, \cdot d, \cdot g /$, las cuales, sin embargo, tendrían una distribución restringida a la posición intervocálica. Por esta razón, en este trabajo se prefiere considerar estos casos como instancias de geminación consonántica /bb, dd, gg/ bobbé volver, oddejá ordeñar, ággo algo.

9. Schwegler 1998 menciona también las prenaslizadas [ $\widehat{\mathrm{nt}}, \widehat{\mathrm{ns}}]$, ntré tres y nse se.

10. En palenquero el significado de este rubro es decir disparates, hablar demasiado (Armin Schwegler, comunicación personal). 
11. Evidentemente, la palabra de saramaca es la reduplicación de la forma reconstruida.

12. El símbolo (-) indica que la palabra correspondiente no se encuentra en las fuentes.

13. Este rubro aparece en uno de los documentos primitivos de papiamento que data de 1775 (Maurer 1998a: 203).

14. El significado de este rubro en saramaca es suegro, yerno y en palenquero es compadre, amigo.

15. Los términos entre paréntesis no están relacionado con el étimo reconstruido. Estos proceden de otras lenguas, especialmente del inglés, en el caso del saramaca; del español, en el caso del papiamento y el palenquero; y del holandés, en el caso del saramaca y el papiamento.

16. La derivación de este étimo desde el portugués es la siguiente: perguntar *perguntá $>$ *peruguntá $>$ *pruguntá $>$ *pruuntá $>$ *pruntá. Los términos del saramaca provienen del protocriollo inglés del Atlánico ask *áaks > ákisi > hákisi. El rubro palenquero entre paréntesis proviene del español: preguntar *preguntá $>$ *preuntá $>$ *preundá.

17. En saramaca, este rubro significa limpiar, pelar y afeitar.

18. Es posible que este rubro también pueda provenir del inglés camp.

19. Este rubro no puede provenir del inglés compass debido al lugar que ocupa el acento en la palabra.

20. Riemer 1779 registra la forma 'barika'.

21. En papiamento, también existe la palabra 'búro, la cual es cognado de la forma palenquera.

22. En papiamento, también existe la forma 'bakaláu, derivada presumiblemente del español.

23. En saramaca, este rubro significa bala.

24. En portugués, la forma correspondiente a este rubro es lamber.

25. Riemer 1779 registra la forma 'jabri'.

26. Este rubro aparece en Riemer 1779 .

27. Este rubro aparece en Riemer 1779 .

28. En saramaca, Riemer 1779 presenta otros ejemplos de esta posición silábica: ‘dubla’ doblar (< port. dobrar), 'pobri' pobre (< port. pobre), 'febre' fiebre (< port. febre).

29. El significado de este marcador en saramaca es de aspecto durativo y en papiamento de tiempo presente.

30. En papiamento, también existe la palabra 'poné, la cual es cognado de la forma palenquera. Estos rubros provienen presumiblemente del español. 
31. En saramaca, el significado de esta palabra es intuir.

32. En saramaca, esta palabra significa gruñir, bramar; en papiamento, además de gritar, significa ladrar, aullar.

33. En saramaca, esta palabra significa universo.

34. En saramaca esta palabra significa viejo.

35. En saramaca, este rubro significa brillar.

36. Riemer 1779 reporta la forma 'dindru'.

37. Riemer 1779 recoge la forma 'dedia'. En esta lengua esta palabra significa también amanecer (daylight).

38. Es probable que las formas di y re estén influenciadas por el español de.

39. Actualmente, también existe la forma sakpí.

40. La derivación de este étimo desde el portugués es la siguiente: rodondo *rudúndu > *rurúndu > *lurúndu > *lulúndu > lulúntu.

41. La reconstrucción de las protoformas inglesas está basada en Portilla 2001 y 2002.

42. En portugués esta palabra significa pecado.

43. Riemer 1779 presenta la forma 'dubla'.

44. Riemer 1779 presenta la forma 'pondri'.

45. Existe, pues, la posibilidad de un origen hispánico de estos rubros, aunque no se trate de términos que puedan ser encontrados en el español estándar moderno. Tal es el caso también, probablemente, de los rubros pap. 'awe pal. awé hoy; pap. 'asỉna pal. asína así.

46. En papiamento, también existe la palabra 'koré, la cual es cognado de la forma palenquera kolé. Ambos rubros provienen presumiblemente del español.

47. Riemer 1779 recoge las formas 'kakkisa' y 'kassika'. La derivación de la forma actual a partir de la protoforma es la siguiente: *káska > kásíka (1779) > ká kísa (1779) > ká kísa.

48. Esta palabra es señalada por Taylor 1977 como arcaica. Riemer 1779 recoge la forma 'komè'. Otra posible interpretación fonológica para este término podría ser kumé.En ese caso, protoforma reconstruida de este étimo sería entonces *kumé. Si esto fuera así, es probable que las formas 'kome del papiamento y komé del palenquero provengan del español y no del protopidgin afroportugués.

49. En inglés la palatalización de las consonante / k / y / g / ante vocales anteriores aparece desde por lo menos mediados del siglo XVII y llega a ser más general en el siglo XVII (Dobson 1968: 952). 
50. En saramaca, este rubro significa sagrar por la nariz. Riemer 1779 reporta la forma 'sangla' sangrar.

51. Este término aparece en Riemer 1779. La forma actual para este rubro es sónde < ing. Sunday.

52. Fonéticamente esta secuencia de los segmentos / ng / se realiza [ $\mathrm{gg}]$.

53. La forma reconstruida correspondiente al protopidgin afroportugués americano es más arcaica que la forma actual del portugués papagaio. Esta es idéntica a la forma original del occitano papagai, la cual dio origen a los rubros de las lenguas ibéricas (Corominas 1983).

54. En portugués la palabra pagamento significa pago, remuneración.

55. En papiamento, también existen las formas (négro, la cual es cognado de la forma palenquera, y (négər, que proviene del holandés.

56. Para la descripción de los cambios en las vocales, véase Portilla 2007.

57. Cf. Portilla 2007, apartado 2.3.c.

58. Esta forma pervive en portugués en el lexema bicho-da-seda 'gusano de seda'.

59. Riemer 1779 reporta la forma 'macharu'.

60. En portugués, este rubro significa cerrar. Riemer recoge la forma 'fitja' con el significado de estrecharse.

61. Riemer 1779 recoge las formas 'floli', 'flolo' y 'froro'. La derivación la forma actual del saramaca a partir de la proforma es la siguiente: *flór $>$ *flóro > flólo (1779) > folólo > foló.

62. Es casi seguro que este rubro ha sido tomado del español, ya que la protoconsonante no aparece en ningún otro caso en posición final absoluta en palabras de origen portugués. En rubros de origen hispánico no recientes, la consonante / $\mathrm{r}$ / original se convierte en una nasal, como en el caso de la palabra la'mán < la mar mar.

63. En portugués, este rubro significa hierro. Riemer 1779 ofrece la forma 'feru' con los significados de hierro y acero.

64. La derivación de esta forma desde el portugués es la siguiente: formiga *fur'míga $>$ *fru'míga > fru'mínga. También, existe en esta lengua la forma vru'mínga.

65. En saramaca, este rubro significa esclavitud actualmente. Riemer 1779 recoge el sentido original. En portugués este significa prisionero.

66. Riemer 1779 presenta la forma 'bila'.

67. Tanto en saramaca como en papiamento este rubro significa cambiar, convertirse.

68. La forma portuguesa corresponde a la conjugación del verbo vir en tercera persona singular del presente. En papiamento, también existe el verbo (bini con el mismo significado, el cual proviene presumiblemente del español venir. 
69. En portugués, la forma correspondiente a este rubro es lança.

70. De acuerdo con la ortografía utilizada por Riemer 1779, la representación fonológica de este rubro sería / lénzu /. Por ejemplo, este autor representa los rubros ánza ala y línzu liso como 'hansa' y 'linsu' respectivamente.

71. En portugués, la forma correspondiente a este rubro es lenço.

72. Riemer 1779 recoge la forma 'parasol'.

73. En las lenguas de la península ibérica, este término proviene directamente del catalán relotge, actualmente rellotge. Sin embargo, en esta lengua, también se registra una forma más antigua arolotge (1368) que conserva la vocal / o / etimológica latina < horologium (Corominas 1983). La derivación de esta palabra desde portugués al papiamento sería la siguiente: relogio $\sim$ rologio / relózio $\sim$ rolózio / > *rolózio > *olózii > *olózi > o'ló fi. La derivación de la forma en saramaca desde el portugués es la siguiente: relogio

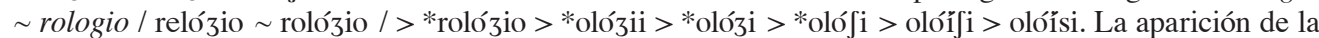
vocal paragógica / i / está propiciada por la consonante alveopalatal siguiente. Otro rubro que presenta este fenómeno es adzóisi adiós. Para este, Riemer 1779 recoge la forma 'adjoshi'.

74. La derivación de esta palabra desde portugués al papiamento sería la siguiente: lagartixa / lagar'ti〔a / > *lagartî́a > *lagardîfa > *lagadîfa > laga'dỉ $\int i$.

75. En saramaca, este rubro significa además tierra, polvo.

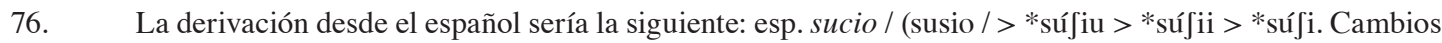
similares ocurren en otros rubros de claro origen hispánico, como por ejemplo ko'dísia $\sim$ ko'dífi codicia, bene'físio bene'fî́i beneficio, 'fîfi oficio, ga'ná Ji ganancia.

77. La forma con una vocal larga es irregular de acuerdo con las reglas de derivación fonológica. Riemer 1779 recoge la forma 'mindja', la cual presenta solo vocales cortas, según lo esperado.

78. Riemer presenta la forma 'markudjà'.

79. El significado de este rubro en saramaca es suegra, nuera y en papiamento es mamá (como forma de tratamiento).

80. La reconstrucción de la forma saramaca está basada en Riemer 1779, quien recoge las formas 'mulêh' y 'moleh'. La forma actual usada en saramaca es déde.

81. En palenquero también exite la forma morỉ, la cual proviene presumiblemente del español.

82. La forma gomitar fue considerada prestigiosa hasta el siglo XVII (Corominas 1983).

83. Riemer 1779 recoge la forma 'mili'.

84. Riemer 1779 presenta la forma 'meki'.

85. La derivación de este rubro en holandés sería la siguiente: automobiel / automo'bi:l / > *tomobỉl > *tomobỉ li > *tombobíli > *tombombỉ li > tombombỉ i. 
86. Esta forma aparece en Riemer 1779, quien también recoge la forma 'bonîta'.

87. Riemer 1779 recoge la forma 'dindra'.

88. La derivación de esta palabra desde portugués al papiamento sería la siguiente: irmão / ir'mãu / > *irmán > *rmán > 'rumán. En el caso del palenquero, la derivación sería la siguiente: irmão / ir'mãu / > *irmán $>$ *rmán > *rumán > *numán > numáno. La adición del marcador de género ocurre, evidentemente, por una influencia posterior del español.

89. $\quad$ Este rubro proviene del español mañana.

90. La forma reconstruida presenta una consonante nasal palatal que es inesperada de acuerdo con el étimo portugués enganar. Es posible que este rubro en papiamento provenga del español engañar, pero esto no puede ser así para el caso del rubro en saramaca.

91. En papiamento, este rubro significa también ella.

92. En saramaca, este rubro significa además cielo, luna, mes.

93. Este rubro también significa dar fruto y poner (huevos) en estas lenguas.

94. En Riemer, el significado de este rubro es solamente sangrar, al igual que en portugués.

95. En portugués, el significado de este rubro es gruñir, refunfuñar. Además, hay que señalar que la forma reconstruida *gruná es irregular respecto del verbo portugués grunhir.

96. Este rubro aparece en Riemer 1779.

97. Riemer 1779 presenta la forma 'mujêri'.

98. Riemer 1779 presenta la forma 'kujéri'.

99. Riemer 1779 presenta la forma 'tereja'. La forma portuguesa difiere del estándar actual strela.

100. En inglés, este rubro significa miel.

101. Cf. Menéndez Pidal 1904: 121 y ss.

102. Cf. Quesada Pacheco 2000: 80-1.

103. Parece evidente que esta forma consiste en la reduplicación de la forma portuguesa mau 'malo'. En saramaca, como en otras lenguas criollas, la reduplicación se utiliza a menudo como un recurso de intensificación. 


\section{Bibliografía}

Amaro's papiamentu project (www.papiamentu.donamaro.nl).

Arends, Jacques et al. (eds.). 1995. Pidgins and Creoles. An introduction. Amsterdam/ Filadelfia: Benjamins.

Bakker, Peter et al. 1995. "Saramaccan”. En: Arends et al. (eds.), 165- 78.

Bartens, Angela. 1995. Die iberoromanisch-basierten Kreolsprachen: Ansätze der linguistischen Beschreibung. Frankfurt/ Main: Peter Lang.

Bickerton, Derek. 1999. “An old argument revisted”. En: Bruyn et al. (eds.), 253-256.

Bickerton, Derek y Aquiles Escalante. 1970. "Palenquero: A Spanish-based creole of northern Colombia". Lingua. 24: 254-67.

Bruyn, Adrienne et al. (eds.). 1999. Mengelwerk voor Muysken. Amsterdam: Universiteit van Amsterdam.

Cásseres, Solmery. 2005. Diccionario de la lengua afro palenquera- español. Cartagena de Indias: Pluma del Monpox.

Clements, Clancy. 1999. "La monogénesis y la formación de algunos criollos de base portuguesa". En: Zimmermann (ed.), 277-93.

2000. "Evidência para a existência de um pidgin português asiático". En: D’Andrade et al. (eds.), 185-200.

Corominas, Joan. 1983. Diccionario etimológico de la lengua castellana. Madrid: Gredos.

D'Andrade, Ernesto et al. (eds.). 2000. Crioulos de base portuguesa. Actas do Workshop sobre Crioulos de Base Lexical Portuguesa. Braga: Associacão portuguesa de linguística.

Díaz Alayón, Carmen (ed.). 1993. Homenaje a Pérez Vidal. Santa Cruz de Tenerife: Romero.

Dobson, E. 1968. English pronunciation 1500-1700. Oxford: Clarendon Press.

Friedemann, Nina S. de y Carlos Patiño. 1983. Lengua y sociedad en el palenque de San Basilio. Bogotá: Instituto Caro \& Cuervo. 
Gadelii, Kart y Anne Zribi-Hertz (eds.). 2007. Grammaires créoles et grammaire comparative. Saint-Denis: Presses Universitaires de Vincennes.

Gilbert, Glenn (ed.). 1987. Pidgin and Creole languages: Essays in memory of John E. Reinecke. Honolulu: University of Hawaii Press.

Goodman, Morris. 1987. "The Portuguese element in American Creoles”. En: Gilbert (ed.), 361-405.

Granda, Germán de. 1970. “Un temprano testimonio sobre las hablas 'criollas' en África y América”. Thesaurus. 25 (1): 1-11.

1974. "El repertorio lingüístico de los sefarditas de Curacao durante los siglos XVII y XVIII y el problema del origen del papiamento". Romance Philology. 28: 1-16.

Grimes, Joseph (ed.). 1972. Languages of the Guianas. México: SIL.

Holm, John.1989. Pidgins and creoles. Vol. 2. Cambridge: Cambridge University Press.

Huber, Magnus y Mikael Parkvall (eds.). 1999. Spreading the word. Londres: Westminter University Press.

Huttar, George. 1972. “A comparative word list for Djuka”. En: Grimes (ed.), 12-21.

Kouwenberg, Silvia y Pieter Muysken. 1995. “Papiamento”. En: Arends et al. (eds.), 205-18.

Lipski, John. 2002. “Génesis y evolución de la cópula en los criollos afroibéricos”. En: Moñino y Schwegler (eds.), 65-101.

Maduro, Antoine. 1987. Palenkero i papiamentu. Korsou.

Maurer, Philippe. 1998a. "El papiamento de Curazao”. En: Perl \& Schwegler (eds.), 139-218.

1998b. Les modifications temporelles et modales du verbe dans le papiamento de Curaçao. Avec une antologie et un vocabulaire papiamento-français. Hamburgo: Helmut Buske.

McWhorter, John. 1999. "The afrogenesis hypothesis of plantation Creole origin”. En: Huber y Parkvall (eds.), 111-52.

Megenney, William.1983. "La influencia del portugués en el palenquero colombiano". Thesaurus. 28: 548-563. 
1986. El palenquero. Un lenguaje post-criollo de Colombia. Bogotá: Instituto Caro y Cuervo.

Menéndez Pidal, Ramón. 1904. Manual de gramática histórica española. Madrid: Espasa-Calpe.

Moñino, Yves. 2007. "Les rôles du substrat dans les créoles et les langues secrètes: le cas du palenquero, créole espagnol de Colombie”. En: Gadelii y Zribi-Hertz (eds.), 49-72.

Moñino, Yves y Armin Schwegler (eds.). 2002. Palenque, Cartagena y Afro-Caribe. Historia y lengua. Tübingen: Niemeyer.

Papiamento-English/ English-Papiamento lexicon (http://www.ats-group.net/dictionaries/ dictionary-english-papiamento.html)

Patiño, Carlos. 2002. “Sobre origen [sic] y composición del criollo palenquero”. En: Moñino y Schwegler (eds.), 21-49.

Perl, Matthias. 1989a. "Algunos resultados de la comparación de fenómenos morfosintácticos del habla bozal, de la linguagem dos musseques, del palenquero y de las lenguas criollas de base portuguesa." Estudios sobre el español de América y lingüística afroamericana. Bogotá: Instituto Caro y Cuervo, 369-380.

1989b. "Portuguiesch un crioulo in Afrika. Geschichte. Grammatik. Lexik. Sprachentwicklung”. Leipzig: Karl-Marx-Universität.

1990. "A reevaluation of the importance of early pidgin/creole Portuguese". Journal of Pidgin and Creole languages. 5: 125-30.

Perl, Matthias et al. (eds.).1993. Portugiesich-basierte Kreolsprachen. Frankfurt: TFM.

Perl, Mathias y Armin Schwegler (eds.).1998. América negra. Panorámica actual de los estudios lingüísticos sobre variedades hispanas, portuguesas y criollas. Frankfurt/ Madrid: Vervuert/Iberoamericana.

Portilla, Mario. 2001. "Reconstrucción del sistema fonológico del protocriollo inglés del Atlántico: Las vocales”. Revista de Filología y Lingüística de la Universidad de Costa Rica. 27 (2): 199-227.

2002. "Reconstrucción del sistema fonológico del protocriollo inglés del Atlántico: Las consonantes". Revista de Filología y Lingüística de la Universidad de Costa Rica. 28 (1): $165-87$. 
2007. "Reconstrucción fonológica del pidgin afroportugués americano: Las vocales". Revista de Filología y Lingüística de la Universidad de Costa Rica. 33 (2): 131-49.

2008. "Protopidgin afroportugués americano". Revista Internacional de Lingüística Iberoamericana (RILI). 6 (1): 161-83.

Quesada Pacheco, Miguel Ángel. El español de América. Cartago: Editorial Tecnológica de Costa Rica.

Riemer, Johann Andreas. 1779. Wörterbuch zur Erlernung der Saramakka-Neger-Sprache. www.sil.org/americas/suriname/Riemer/National/RiemerNLDict.

Rountree, S. 1972. “The phonological structure of stems in Saramaccan”. En: Grimes (ed.), 22-27.

Saramaccan - English Dictionary. www.sil.org/americas/suriname/Saramaccan/English/ SaramEngDictIndex.

Smith, Norval. 1995. "An annotated list of creoles, pidgins, and mixed languages". En: Arends et al. (eds.), 331-374.

Stolz, Thomas. 1987. "Verbale morphosyntax der portugiesisch-basierten Kreols". Iberoamericana. 11: 35-59.

Schwegler, Armin. 1991. "Zur Problematik der afroportugiesischen Kontaksprache in Amerika: Nenes aus El Palenque de San Basilio (Kolumbien)". Lusorama. 15: 54-79.

1993. "Rasgos (afro-) portugueses en el criollo de Palenque de San Basilio (Colombia)". En: Díaz Alayón (ed.), 667-696.

1998. "El palenquero”. Perl \& Schwegler (eds.), 1998: 218-91.

Taylor, Douglas. 1977. Languages of the West Indies. Baltimore/Londres: The Johns Hopkins University Press.

Voorhoeve, Jan. 1959. “An orthography for Saramacca”. Word. 15: 436-45.

Whinnom, Keith. 1965. "Origin of European-based creoles and pidgins”. Orbis. 14 (2): 509-27.

Zimmermann, Klaus (ed.). 1999. Las lenguas criollas de base lexical española y portuguesa. Frankfurt/Madrid: Vervuert/Iberoamericana. 